\title{
CityComfort+: A Simulation-Based Method for Predicting Mean Radiant Temperature in Dense Urban Areas
}

\author{
Jianxiang Huang $^{a *}$, Jose Guillermo Cedeño-Laurent ${ }^{b}$ John D. Spengler ${ }^{b}$ \\ ${ }^{a}$ The University of Hong Kong, Department of Urban Planning and Design \\ ${ }^{\mathrm{b}}$ Harvard University School of Public Health \\ * Corresponding author. Tel.: +852-2219 4991; E-mail: jxhuang@hku.hk (J. Huang). Address: 8/F, \\ Knowles Building, The University of Hong Kong, Pokfulam Road, Hong Kong
}

\begin{abstract}
This paper introduces CityComfort+, a new method to simulate the spatial variation of the mean radiant temperature $\left(T_{m r t}\right)$ in dense urban areas. This method derives the $T_{\text {mrt }}$ by modeling five components of radiation fluxes—direct solar radiation, diffuse solar radiation, reflected solar radiation, long-wave radiation from the atmosphere, and long-wave radiation from urban surfaces-each weighted by view factors. The novelty of CityComfort+ lies in a new algorithm to model surface temperature and associated long-wave radiation as well as the application of RADIANCE, a ray-tracing algorithm that can accurately simulate 3-D radiation fluxes in a complex urban space (Ward, et al, 1998). CityComfort+ was evaluated in field studies conducted in a dense urban courtyard (mean sky view factor of 0.4 ) in Boston, Massachusetts, USA under winter, spring, and summer (cold, warm, and hot) weather conditions. Simulation results yielded close agreement with measured $\mathrm{T}_{\text {mrt }}$. Also, predicted mean surface temperature agreed well with the measurement data. A sensitivity test using CityComfort+ revealed that $T_{m r t}$ on the study site will be mostly affected by the heat capacity and emissivity of surface material, not albedo.. This study is subject to limitations from sensor accuracy and the thermal inertia of the grey ball thermometer, and the CityComfort+ method is still under development. The next step is to compare its performance with existing methods.
\end{abstract}

Keywords: Mean Radiant Temperature, Simulation, Outdoor Thermal Comfort

\section{Introduction}


The mean radiant temperature $\left(T_{\mathrm{mrt}}\right)$ is among the most important variables affecting human thermal comfort in an outdoor urban space (Lindberg et al., 2008). $T_{m r t}$ is the uniform temperature of an imaginary enclosure in which radiant heat transfer from the human body is equal to those in the actual non-uniform enclosure (ISO, 1998). It is the composite mean temperature of the body's radiant environment. Compared with convection or evaporation, radiative energy exchange accounts for a large share of human heat transfer ${ }^{1}$ (Folk, 1974) and it is closely correlated with outdoor thermal comfort as well as pedestrian activities Whyte, 1980; Nikolopoulou et al., 2006). For this reason, there is a practical need to model radiative heat transfer between human body and the built environment. Once $T_{\text {mrt }}$ is known in an actual urban space, it will be one step forward to assess human body heat balance, which will enable us to predict and mitigate thermal stress in the context of rising urban heat island effect (UHI) and more frequent extreme weather conditions (IPCC, 2013).

$\mathrm{T}_{\text {mrt }}$ varies temporarily and spatially in cities where urban surfaces interact with radiation, absorbing, reflecting, or emitting radiative energy at various wave-lengths. Field measurements using a dense sensor network is impractical and cost-prohibitive. Recently, a few methods have been developed to simulate $T_{\text {mrt }}$ in urban spaces, including Rayman 1.2 (Matzarakis et al., 2010), ENVI-met 3.1 (Bruse, 2009), and SOLWEIG 2.2 (Lindberg et al, 2008), but each has limitations. Rayman 1.2 is easy to use but can only calculate $T_{m r t}$ at one point at a time, it exhibits significant errors when solar angles are low, and it cannot account for reflected short-wave radiation (Thorsson et al, 2007). ENVI-met can compute $T_{\text {mrt }}$ on a continuous surface, however it cannot process vector-based geometries, so buildings, topography and vegetation must be manually transformed into pixels. A single time-step ENVI-met simulation takes more than $6 \mathrm{~h}$, and its performance in predicting long-wave radiation fluxes matches weakly with field measurement data (Ali Toudert, 2005). SOLWEIG, a fast user-friendly tool, allows data exchange with Digital Elevation Model (DEM), a pixelated geometry format compatible with GIS systems but sacrifices 3-

${ }^{1}$ In a typical indoor space with the temperature of the air of $24{ }^{\circ} \mathrm{C}$, the skin of $32{ }^{\circ} \mathrm{C}$, and the $\mathrm{T}_{\text {mrt }}$ of $21^{\circ} \mathrm{C}$, radiant heat loss accounts for two thirds of the total heat transferred from human body to the environment (Folk, 1974). 
D geometry details; SOLWEIG's formula on diffused and reflected solar radiation is overly simplified and demonstrates errors in dense urban spaces. Other methods include SPOTE (Lin et al., 2006) and TOWNSCOPE (Teller et al., 2001) which are unavailable in the public domain.

This paper introduces a new method, CityComfort+, to simulate $T_{\text {mrt }}$ in urban areas of varying densities. CityComfort+ has been developed in support of urban planning and landscape architectural practices.. The novelty of this method lies in using RADIANCE, a state-of-the-art day lighting simulation software (Ward, et al, 1998) to calculate short-wave radiation. Meanwhile, CityComfort+ applies a new algorithm to estimate long-wave radiation from urban surfaces. RADIANCE was previously used to simulate lighting in an urban environment but not $\mathrm{T}_{\text {mrt }}$, since it is not equipped to model surface temperature variations of buildings and the ground. CityComfort+ takes simple data inputs, including weather data and 3-D urban geometries in vector format (using geometrical shapes instead of pixels to describe buildings and topographies). The results are $\mathrm{T}_{\mathrm{mrt}}$ in urban spaces of high spatial-temporal resolution. The CityComfort+ method has been evaluated using field measurement data collected in Boston, Massachusetts, USA under cold, warm, and hot weather conditions. Predicted $\mathrm{T}_{\text {mrt }}$ and mean surface temperature using CityComfort+ agreed closely with measurement data.

\section{Model for mean radiant temperature}

By definition, $T_{m r t}$ is the uniform temperature of an imaginary enclosure that cannot be measured directly. $\mathrm{T}_{\mathrm{mrt}}$ can be expressed by Formula 1 as the fourth root of the integration of individual radiation components, each weighted by the view factor from the source to a person (ASHRAE, 2009).

Formula 1

$\mathrm{T}_{\mathrm{mtt}}=\sqrt[4]{\left(\varepsilon_{1} \cdot \mathrm{T}_{1}^{4} \cdot \mathrm{F}_{1 \rightarrow \mathrm{p}}+\varepsilon_{2} \cdot \mathrm{T}_{2}^{4} \cdot \mathrm{F}_{2 \rightarrow \mathrm{p}}+\ldots+\varepsilon_{\mathrm{n}} \cdot \mathrm{T}_{\mathrm{n}}^{4} \cdot \mathrm{F}_{\mathrm{n} \rightarrow \mathrm{p}}\right)}$

$\varepsilon_{\mathrm{n}} \quad=$ Emissivity for surface materials (ratio, 0-1)

$\mathrm{T}_{\mathrm{n}} \quad=$ Temperature of isothermal surfaces $(\mathrm{K})$

$F_{n \rightarrow p}=$ View factor between isothermal surfaces and a person (ratio, 0-1) 


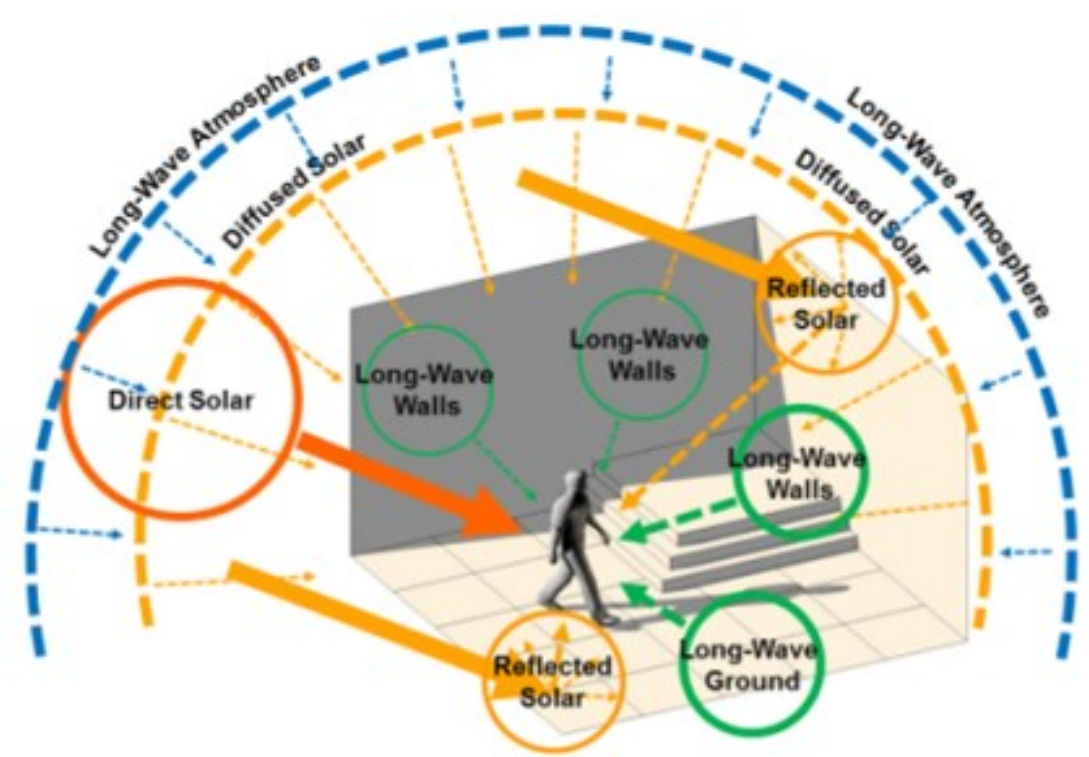

Fig. 1. Components of $\mathrm{T}_{\mathrm{mrt}}$ in an urban environment in CityComfort+

Radiative energy in an urban environment consists of three primary components: 1) solar radiation, 2) atmospheric long-wave radiation, 3) long-wave radiation from urban surfaces (Fig. 1). $T_{\text {mrt }}$ equals the fourth root of the integration of mean radiation energy intensity from three components weighted by their view factors (Formula 2).

Formula 2

$$
\begin{aligned}
& \mathrm{T}_{\mathrm{mrt}}=\sqrt[4]{\frac{1}{\sigma}\left(a_{p} \cdot \mathrm{E}_{\text {sol }} \cdot \mathrm{F}_{\mathrm{sol} \rightarrow \mathrm{p}}+\varepsilon_{\text {sky }} \cdot \mathrm{E}_{\mathrm{sky}} \cdot \mathrm{F}_{\mathrm{sky} \rightarrow \mathrm{p}}+\varepsilon_{\mathrm{urb}} \cdot \mathrm{E}_{\mathrm{urb}} \cdot \mathrm{F}_{\mathrm{urb} \rightarrow \mathrm{p}}\right)} \\
& \sigma=\text { Stephan-Boltzmann Constant }\left(5.67 \times 10^{-8} \mathrm{~W} / \mathrm{m}^{2} \mathrm{~K}^{4}\right) \\
& a_{p} \quad=\text { Absorption coefficient of solar radiation for a person (standard 0.7) } \\
& \varepsilon_{\text {sky }} \quad=\text { Emissivity of the sky (ratio, 0-1) } \\
& \varepsilon_{\text {urb }}=\text { Emissivity of solid surfaces (ratio, 0-1) } \\
& \mathrm{E}_{\mathrm{sol}} \quad=\text { Solar radiation intensity }\left(\mathrm{W} / \mathrm{m}^{2}\right) \\
& E_{\text {sky }} \quad=\text { Long-wave radiation intensity of the sky }\left(\mathrm{W} / \mathrm{m}^{2}\right) \\
& E_{\text {urb }} \quad=\text { Long-wave radiation intensity of urban surfaces }\left(\mathrm{W} / \mathrm{m}^{2}\right) \\
& \mathrm{F}_{\mathrm{sol} \rightarrow \mathrm{p}}=\text { View factor between the short-wave sources and a person (ratio, 0-1) } \\
& F_{\text {sky } \rightarrow p}=\text { View factor between the visible sky and a person (ratio, 0-1) } \\
& F_{\text {urb } \rightarrow p}=\text { View factor between urban surfaces and a person (ratio, 0-1) }
\end{aligned}
$$




\section{1 Solar radiation}

Solar radiation is a strong and volatile source of radiative heat flux. A plausible simulation model needs to account for direct, diffused, and reflected sunlight. These components can be accounted for using the ray-tracing algorithm, a computing technique that traces the path of light and simulates its interactions with urban geometries.

To simulate solar radiation in a dense urban area, CityComfort+ applies RADIANCE, a highly accurate day lighting simulation software that has been extensively studied in the past decade (Mardaljevic, 1995, Reinhart et al, 2001, Ward, et al, 1998). 3-D urban geometries are processed using the DIVA-for-Rhino 2.0 plug-in (Jakubiec et al, 2011), a graphical user interface based on Rhinoceros (McNeel, 2010). Data of global horizontal irradiance, usually available from a nearby weather station, can be split into direct normal irradiance and diffuse horizontal irradiance using the Reindl method (Reindl, 1990). The outputs are intensity of direct, diffused, and reflected radiation received at a predefined grid of sensors. Details of RADIANCE simulation are included in Appendix B; the workflow above is automated using the programming language Python.

\subsection{Long-Wave Radiation from the Atmosphere}

Atmospheric long-wave radiation can be estimated as a function of ambient air temperature, vapor pressure, and cloud cover using the Angstrom formula (Angstrom, 1918) (Formula 3). The Angstrom formula was evaluated using data from 21 sites and it was proven to be among the best algorithms under clear sky conditions (Flerchinger, 2009). The degree of cloudiness can be estimated from the ratio between measured global horizontal irradiance and the modeled irradiance under the clear-sky condition (Lindberg et al, 2008) (Formula 4). The vapor pressure $V_{p}$ can be computed using the Arden Buck equation (Buck,1981) (Formula 5).

Formula 3

$$
\begin{aligned}
& E_{a}=\sigma \cdot\left(T_{a}+273.15\right)^{4} \cdot\left(0.82-0.25 \cdot 10^{-0.0945 V_{p}}\right) \cdot\left(1+0.21 \cdot\left(\frac{N}{8}\right)^{2.5}\right) \\
& \mathrm{E}_{\mathrm{a}} \quad=\text { Downward atmospheric long-wave irradiance }\left(\mathrm{W} / \mathrm{m}^{2}\right) \\
& \mathrm{T}_{\mathrm{a}} \quad=\text { Dry bulb temperature }\left({ }^{\circ} \mathrm{C}\right) \\
& \mathrm{N} \quad=\text { Degree of cloudiness (Octas) }
\end{aligned}
$$


$\mathrm{V}_{\mathrm{p}} \quad=$ Vapor pressure $(\mathrm{hPa})$

Formula 4

$\mathrm{N}=1-\mathrm{E}_{\mathrm{sol}} / \mathrm{E}_{\mathrm{mol}}$

$E_{\text {sol }} \quad=$ Measured solar irradiance $\left(\mathrm{W} / \mathrm{m}^{2}\right)$

$\mathrm{E}_{\mathrm{mol}} \quad=$ Modeled solar irradiance under clear sky $\left(\mathrm{W} / \mathrm{m}^{2}\right)$

Formula 5

$V_{p}=R_{\text {hum }} 6.1121 \cdot \exp \left(\left(18.678-\frac{T_{a}}{234.4}\right) \cdot\left(\frac{T_{a}}{257.14+T_{a}}\right)\right)$

$\mathrm{V}_{\mathrm{p}} \quad=$ Water vapor pressure $(\mathrm{hPa})$

$\mathrm{R}_{\text {hum }} \quad=$ Relative humidity (\%)

$\mathrm{T}_{\mathrm{a}} \quad=$ Dry bulb temperature $\left({ }^{\circ} \mathrm{C}\right)$

\subsection{Long-wave radiation from urban surfaces}

CityComfort+ applies a first-principles method to estimate long-wave radiation from urban surfaces, which is determined by surface temperature, material emissivity, and long-wave radiation reflected from the ambient environment. According to Stephan-Boltzmann's law, the total long-wave radiation intensity $E_{g}$ from objects at typical atmospheric temperatures is the aggregation of those each urban surface (Formula $6)$.

$$
\begin{aligned}
& \text { Formula } 6 \\
& \mathrm{E}_{g}=\frac{\sum_{i=1}^{n}\left(\varepsilon_{i} \cdot \sigma \cdot \mathrm{T}_{\mathrm{s}}^{4}+\left(1-\varepsilon_{i}\right) \cdot \varepsilon_{i} \cdot \sigma \cdot \mathrm{T}_{\mathrm{e}}^{4}\right) \cdot \mathrm{F}_{\mathrm{i}}}{\sum_{i=1}^{n} \mathrm{~F}_{\mathrm{i}}} \\
& \mathrm{E}_{\mathrm{g}} \quad=\text { Overall long-wave radiation intensity from urban surfaces }\left(\mathrm{W} / \mathrm{m}^{2}\right) \\
& \mathrm{i} \quad=\text { Number of urban surfaces } \\
& \left.\varepsilon_{\mathrm{i}} \quad=\text { Emissivity of surface material(ratio, } 0-1\right) \\
& \sigma \quad=\text { Stephan-Boltzmann's constant }\left(5.67 \times 10^{-8} \mathrm{~W} / \mathrm{m}^{2} \mathrm{~K}^{4}\right) \\
& \mathrm{F}_{\mathrm{i}} \quad=\text { View factor of solid surface }(\text { ratio) } \\
& \mathrm{T}_{\mathrm{s}} \quad=\text { Mean temperature at the surface plane }(\mathrm{K}) \\
& \mathrm{T}_{\mathrm{e}} \quad=\text { Ambient radiant temperature at the surface plane }(\mathrm{K})
\end{aligned}
$$


CityComfort+ categorizes urban surfaces into one of the four groups: 1) sunlit walls, 2) shaded walls, 3) sunlit ground, 4) shaded ground. It assumes isothermal conditions hold for each group, in which the surface temperature $T_{s}$ remains constant for all surfaces within the same group. Each surface group observes the heat balance equation among radiation, convection, conduction, and thermal massing effects (Fig. 2). $T_{s}$ is a function of DNI, DHI, solar altitude angle, sky view factor, surface albedo, emissivity, specific heat capacity, material density, average $U$-values for external walls and the ground, building internal temperature and soil temperature (Formula 7 is the equilibrium case). The initial value for $\mathrm{T}_{\mathrm{s}}$ before sunrise is set to equal $3.4 \mathrm{~K}$ below the ambient air temperature, an assumption derived from empirical studies in Gothenburg (Lindberg et al, 2008).

The four-group assumption in CityComfort+ is a simplified alternative to exhaustive computing of temperature for each surface. The later method is computationally expensive and potentially ineffective, since information on surface thermal properties is seldom complete, which might compromise performance gains.

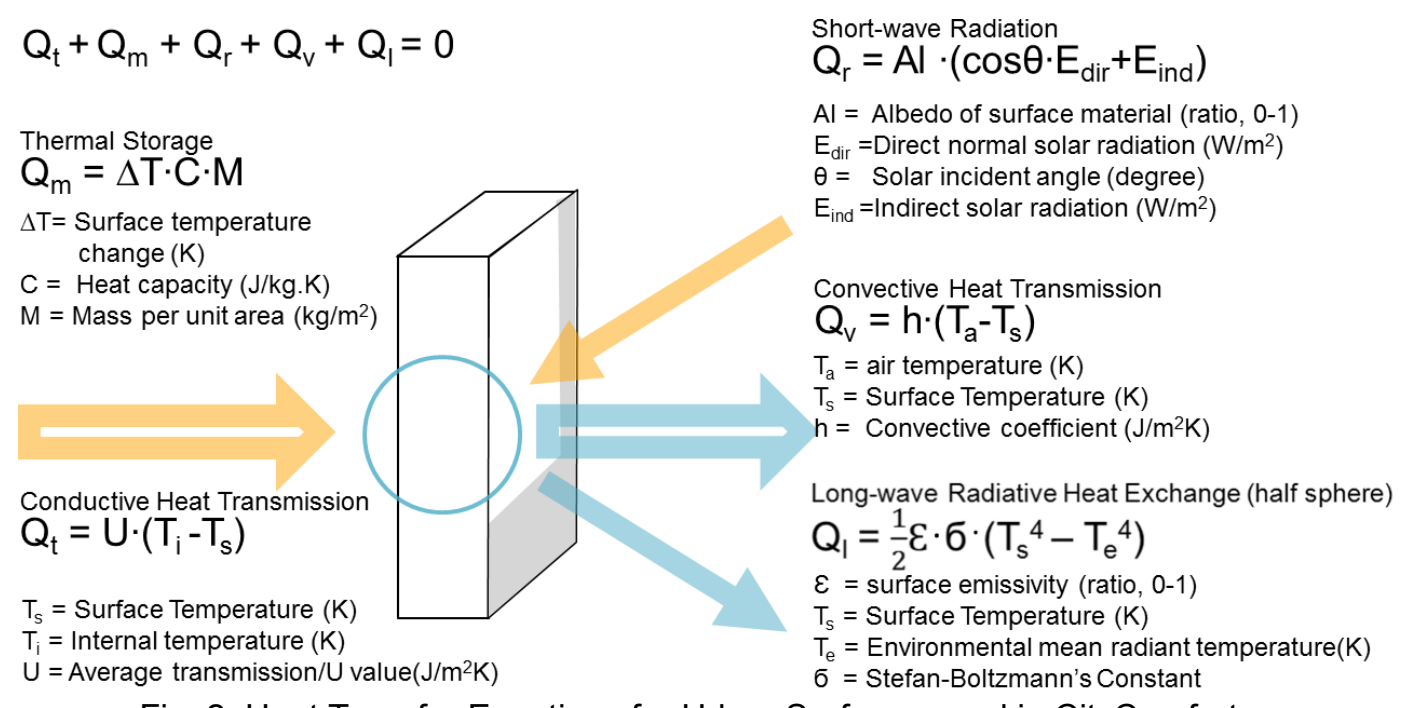

Fig. 2. Heat Transfer Equations for Urban Surfaces used in CityComfort+

Formula 7 (assumes equilibrium)

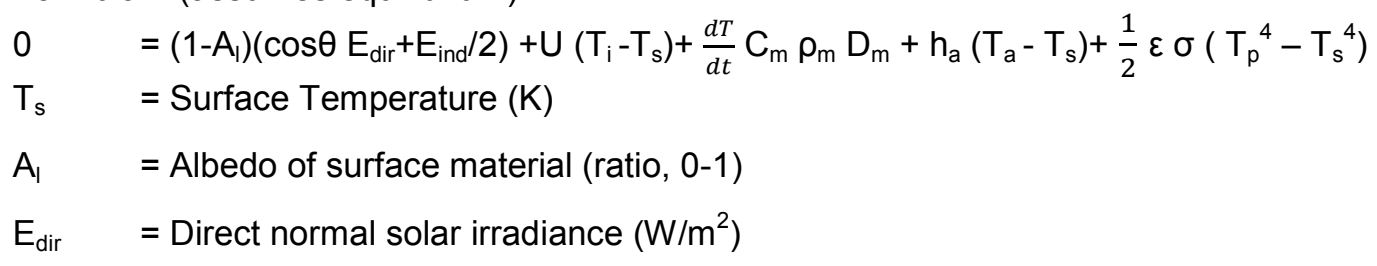




$$
\begin{array}{ll}
E_{\text {ind }} & =\text { Indirect solar irradiance }\left(\mathrm{W} / \mathrm{m}^{2}\right) \\
\theta & =\text { Solar incident angle (degree) } \\
T_{\mathrm{i}} & =\text { Internal temperature inside the building or the underground soil }(\mathrm{K}) \\
\mathrm{U} & =\text { Heat transmission coefficient for buildings or soil }-\mathrm{U} \text { value }\left(\mathrm{W} / \mathrm{m}^{2} \mathrm{~K}\right) \\
\mathrm{dT} & =\text { Surface temperature reduction from previous time-step }(\mathrm{K}) \\
\mathrm{dt} & =\text { Calculation time-step (Second) } \\
\mathrm{C}_{\mathrm{m}} & =\text { Surface material specific heat capacity }(\mathrm{J} / \mathrm{kg} \cdot \mathrm{K}) \\
\rho_{\mathrm{m}} & =\text { Material density }\left(\left(\mathrm{kg} / \mathrm{m}^{3}\right)\right. \\
\mathrm{D}_{\mathrm{m}} & =\text { Surface depth }(\mathrm{m}) \\
\mathrm{M} & =\text { Mass per unit area }\left(\mathrm{kg} / \mathrm{m}^{2}\right) \\
\mathrm{T}_{\mathrm{a}} & =\text { air temperature }(\mathrm{K}) \\
\mathrm{h}_{\mathrm{a}} & =\text { Convective coefficient }\left(\mathrm{J} / \mathrm{m}^{2} \mathrm{~K}\right) \\
\varepsilon & =\text { surface emissivity }(\mathrm{ratio}, 0-1) \\
\sigma & =\text { Stephan-Boltzmann's constant }\left(5.67 \times 10^{-8} \mathrm{~W} / \mathrm{m}^{2} \mathrm{~K}^{4}\right) \\
\mathrm{T}_{\mathrm{p}} & =\text { Plane radiant temperature at the surface }(\mathrm{K})
\end{array}
$$

The plane radiant temperature at the surface $\left(T_{p}\right)$ is the view-factor-weighted mean between the radiant temperature of the visible sky and surrounding surfaces $\left(T_{s r}\right) . T_{p}$ can be expressed as a function of downward atmospheric long-wave irradiance $\left(E_{a}\right)$, air temperature $\left(T_{a}\right)$, and sky view factor $\Psi$ in Formula 8. The definition and calculation of $\Psi$ is specified in the following section.

Formula 8

$$
\begin{array}{ll}
\mathrm{T}_{\mathrm{p}} & =\sqrt[4]{E_{a} \cdot F_{s k y \rightarrow \mathrm{s}}+\sigma \cdot\left(T_{s r}+273.15\right)^{4} \cdot F_{\mathrm{urb} \rightarrow \mathrm{s}}}-273.15 \\
\mathrm{E}_{\text {ind }} & =\text { Indirect solar irradiance }\left(\mathrm{W} / \mathrm{m}^{2}\right) \\
\mathrm{E}_{\mathrm{a}} & =\text { Downward atmospheric long-wave irradiance }\left(\mathrm{W} / \mathrm{m}^{2}\right) \\
\mathrm{T}_{\mathrm{sr}} & =\text { Average temperature of the visible urban surfaces. } \\
\mathrm{F}_{\mathrm{sky} \rightarrow \mathrm{s}} & =\text { View factor between the sky and the plane. }
\end{array}
$$$$
\text { For vertical wall } F_{s k y \rightarrow s}=\Psi / 2 \text {; For horizontal ground } F_{s k y \rightarrow s}=\Psi
$$$$
\mathrm{F}_{\mathrm{urb} \rightarrow \mathrm{s}}=\text { View factor between visible urban surfaces and the plane. }
$$$$
\text { For vertical wall } F_{\text {sky } \rightarrow s}=1-\Psi / 2 \text {; For horizontal ground } F_{s k y \rightarrow s}=1-\Psi
$$

It will be computationally demanding to model surface radiative interactions in an urban environment. To solve $T_{p}$, a simplification is made to equal $T_{s r}$ with those of the ambient air $\left(T_{s r}=T_{a}\right)$, assuming heat 
exchange occurs thoroughly between solid surfaces and air within the canopy layer. Uncertainties associated with this assumption are analyzed in comparison with measurement data.

\section{2. $4 \quad$ View factors}

The view factor is the proportion of radiative energy that is transmitted from the surfaces of the source to those of the destination. For a person, the view factor of a given source $F_{s \rightarrow p}$ is the projection area on the person divided by his/her total surface area. $\mathrm{F}_{\mathrm{s} \rightarrow \mathrm{p}}$ is dependence on radiation source and also on bodily posture.

The view factor between the human body and direct sunlight, i.e., the direct normal solar irradiance $\left(E_{\text {dir }}\right)$, can be estimated using the Human Body Projection Area factor $\left(F_{p}\right)$. For a standing person, $F_{p}$ is a function of the solar altitude and azimuth angle expressed by Formula 9 and it is largely independent of gender, body size and shape (Underwood, et al. 1966). For a sitting person, $F_{p}$ is close to that of a sphere $\mathrm{F}_{\mathrm{s}}$, where $\mathrm{F}_{\mathrm{p}} \approx \mathrm{F}_{\mathrm{s}}=0.25$

$$
\begin{aligned}
& \text { Formula } 9 \\
& \begin{array}{ll}
\mathrm{F}_{\text {dir } \rightarrow \mathrm{p}}= & \mathrm{F}_{p}=0.0355 \sin \beta+2.33 \cdot \cos \beta \cdot \sqrt{0.0213 \cos ^{2} \alpha+0.0091 \sin ^{2} \alpha} \\
\alpha \quad= & \text { Solar azimuth angle (degree }-45^{\circ} \text { for a standard person) } \\
\beta \quad=\text { Solar altitude angle (degree) }
\end{array}
\end{aligned}
$$

The view factors between the human body and indirect radiation sources are estimated using the sky view factor $(\psi)$, the proportion of spherical area of non-obscured open sky to the area of the upper sphere. $\psi$ can be conveniently calculated in RADIANCE using methods stated in Appendix B. Bodily postures such as sitting or standing makes negligible differences in indirect radiative energy received by a person. View factor for diffused and reflected sunlight $\left(F_{\text {ind } \rightarrow p}\right)$ equals those of the sky and of sunlit wall surfaces.

View factor for downward atmospheric long-wave irradiance $\left(F_{\text {sky } \rightarrow p}\right)$ equals $\psi / 2$ (Table 1$)$.

Table 1. View factor by radiation components Radiation Components View Factors

Direct solar radiation for a standing person

Direct solar radiation for a sitting person
$0.0355 \sin \beta+2.33 \cdot \cos \beta \cdot \sqrt{0.0213 \cos ^{2} \alpha+0.0091 \sin ^{2} \alpha}$ 0.25 
Diffused and reflected solar radiation

Upward reflected solar radiation

Atmospheric long-wave radiation

Surface long-wave radiation

\section{$\Psi / 2+V_{\text {slw }}{ }^{*}$ \\ 0.5 \\ $\Psi / 2$ \\ $1-\Psi / 2$}

${ }^{*} V_{\text {slw }}$ : view factor of wall surfaces exposed to direct sunlight

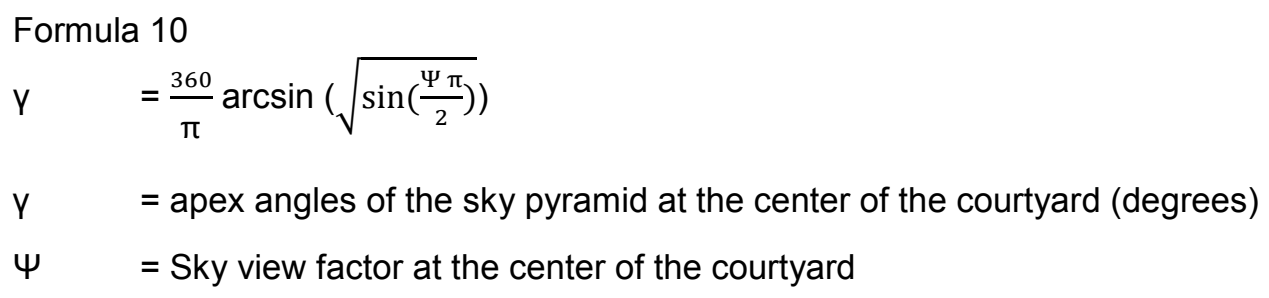

The view factors for the four surface groups are estimated using a simplified courtyard illustrated in Fig. 3. The ratio between the width and height of the yard is a function of the sky view factor $(\Psi)$ at the center, and the apex angles of the sky pyramid $(\gamma)$ can be expressed using $\Psi$ alone (Formula 10). Table 2 summarizes the view factors for each surface group. The aggregate view factor for four groups $\left(F_{\text {urb } \rightarrow p}\right)$ equals $1-\Psi / 2$.

Table 2. View factors for sunlight and shaded urban surfaces calculated based on the urban courtyard shown in Fig. 3

View Factors

\begin{tabular}{lcc} 
& $\beta \leq \tan ^{-1}\left(\frac{1}{2 \tan \frac{\gamma}{2}}\right)$ & $\beta>\tan ^{-1}\left(\frac{1}{2 \tan \frac{\gamma}{2}}\right)$ \\
\hline Sunlit Walls $\left(\mathrm{V}_{\mathrm{slw}}\right)$ & $\frac{1}{4} \tan \frac{\gamma}{2} \tan \beta(1-\Psi)$ & $\frac{1}{8}(1-\Psi)$ \\
Shaded Walls $\left(\mathrm{V}_{\mathrm{sdw}}\right)$ & $\left(\frac{1-\Psi}{2}\right)\left(1-\frac{1}{2} \tan \frac{\gamma}{2} \tan \beta\right)$ & $\frac{3}{8}(1-\Psi)$ \\
Sunlit Ground $\left(\mathrm{V}_{\mathrm{slg}}\right)$ & 0 & $0.5\left(1-\frac{1}{2 \tan \beta \tan \frac{\gamma}{2}}\right)$ \\
Shaded Ground $\left(\mathrm{V}_{\mathrm{sdg}}\right)$ & 0.5 & $0.5\left(\frac{1}{2 \tan \beta \tan \frac{\gamma}{2}}\right)$
\end{tabular}



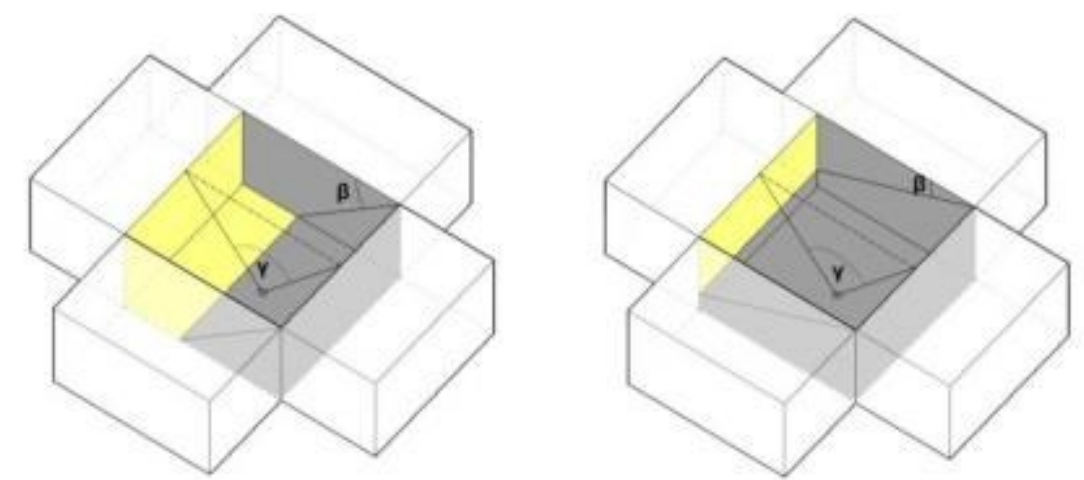

Fig. 3.View factors of sunlit and shaded urban surfaces in an urban courtyard for highest and lowest solar angle.

$\beta=$ Solar attitude; $\gamma=$ apex angles of the sky pyramid at the center of the courtyard

\section{Field study}

The field study was conducted in an urban courtyard in Boston $\left(42^{\circ} 21^{\prime} 29^{\prime \prime} \mathrm{N}, 71^{\circ} 3^{\prime} 49^{\prime \prime} \mathrm{W}\right)$, USA, under three separate weather conditions: cold, moderate, and hot; one day for each condition. Measurements of $T_{\text {mrt }}$ were made at four locations on the study site by four sets of sensors; surface temperature of building walls and the ground were measured at regular intervals; and weather data were collected from an on-site roof-top weather station (Fig. 4).

The site was a 50 m by 25 m rectangular courtyard between the Harvard University Medical School and the School of Public Health. The courtyard was surrounded by solid building walls made of granite stone and concrete tiles; these buildings had small window openings, and the site had a minimum amount of vegetation. The field study took place on January 15, March 21, and August 23 of 2012 for a total of $33 \mathrm{~h}$. The lowest air temperature observed was $-14.4^{\circ} \mathrm{C}$ and the highest was $30.6^{\circ} \mathrm{C}$. Sky conditions alternated between sunny and cloudy, with recorded global horizontal irradiance between 0 to $957 \mathrm{~W} / \mathrm{m}^{2}$ ( Table 3).

Table 3. Summary of meteorological conditions during the field study in Boston.

Janurary 15,2012

March 21, 2012

August 23, 2012

Weather Type

Sunny

Sunny

Sunny - Cloudy

Mean Temperature $\quad{ }^{\circ} \mathrm{C}$

$-10.6$

19.4

25.0

Max Temperature $\quad{ }^{\circ} \mathrm{C}$

$-7.2$

25.6

30.6

Min Temperature

${ }^{\circ} \mathrm{C}$

$-14.4$

13.3

18.9

Average Humidity

(\%)

48

65

59 

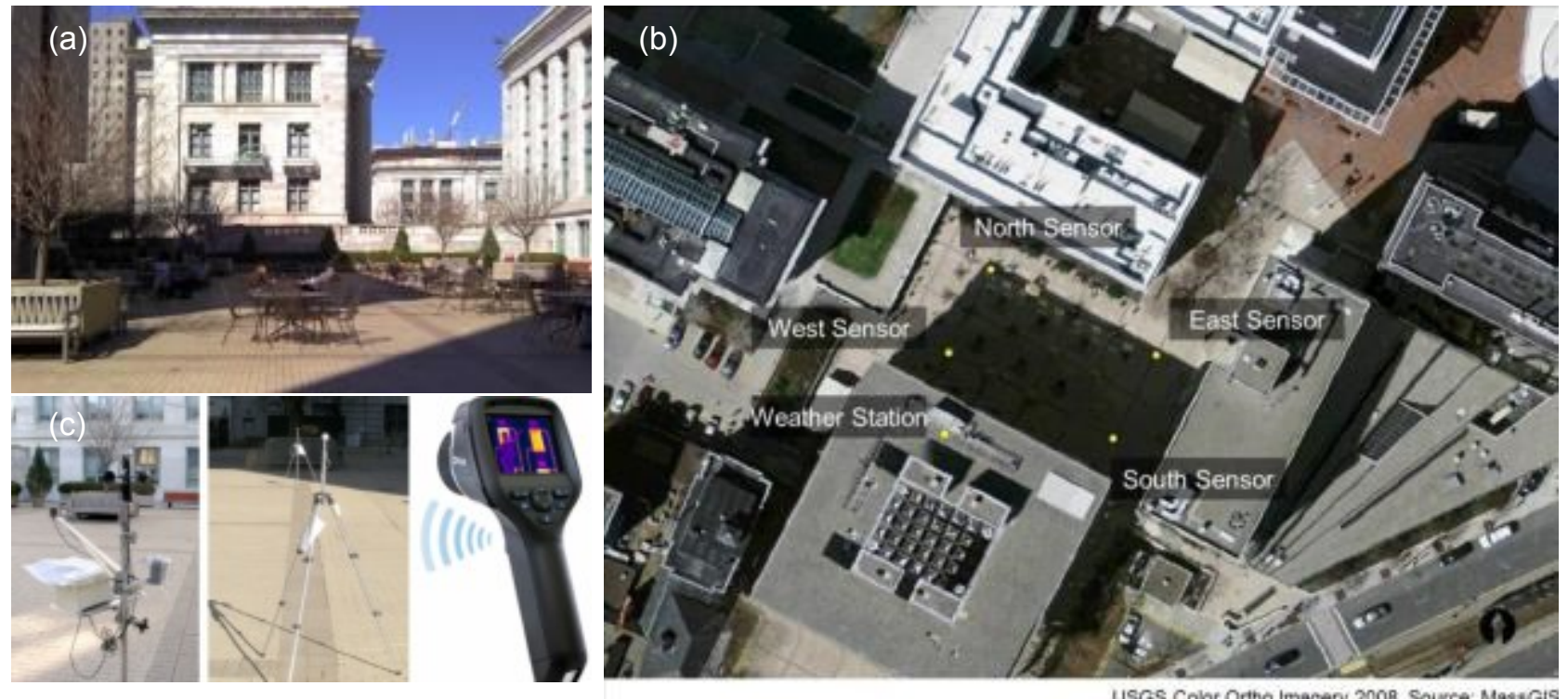

Fig.4. (a) Ground level view (upper left)of the courtyard study site next to Countway Library, Harvard University, Boston; (b) aerial view (right) of the sensor locations in the courtyard; and (c) the portable weather station (lower left), $40 \mathrm{~mm}$ grey-ball Thermometer, and infrared camera.

$\mathrm{T}_{\mathrm{mrt}}$ at the four locations were measured by four grey-ball thermometers mounted 1.5 meter above the ground on tripods. The small globe thermometer had been tested in a previous study, yielding satisfactory results compared with the state-of-the-art six-dimension radiometers (Thorsson et al, 2007). The globe used was $40 \mathrm{~mm}$ in diameter, made of copper and painted grey (albedo $=0.3$; emissivity $=0.95$ ). A temperature sensor (TMC6-HA) was placed inside each globe and it recorded readings into a data logger (U12-006) at five-min intervals. Due to the effect of convective heat loss from the small globe thermometer, measured globe temperature needs to be converted into $T_{m r t}$ by adjusting for convective heat exchange. Formula 11 was derived from Kuehn's study on globe thermometer (Kuehn et al., 1970), where $T_{\text {mrt }}$ is expressed as a function of the globe temperature, localized wind speed, and the air temperature). Localized wind speed was measured on site using anemometers (S-WCA_M003) at $1.5 \mathrm{~m}$ 
above ground with an exception on March $21^{2}$. Details of Kuehn's study on the use of globe thermometer are included in Appendix A.

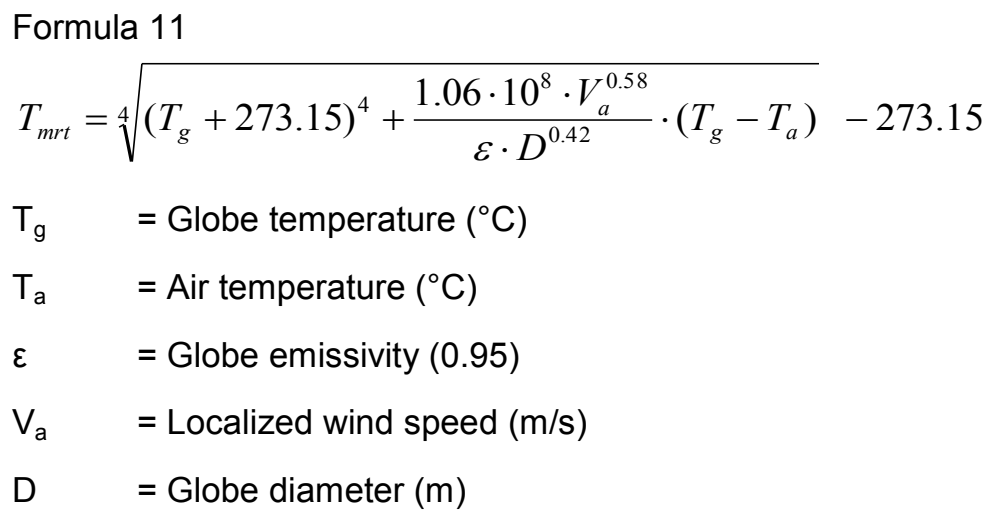

Temperature of the ground and four building facades were measured using an infrared camera (FLIR E40-NIST) at 15-min to 60-min intervals. To account for temperature differences on the same surface, the temperature of each surface was recorded as the mean value measured at four fixed spots. Weather data were collected for the CityComfort+ simulation as follows: Ambient air temperature and humidity were measured $1.5 \mathrm{~m}$ above ground using portable sensors (S-THB-M002). Global horizontal irradiance data were collected every five min from the Harvard Arboretum weather station (KMAJAMAI4), three km from the study site. For August 2012, solar irradiance data became available from an on-site weather station (Onset Computer Corporation S-LIB-M003) installed on the rooftop of the Countway Library.

In parallel to the field study, CityComfort+ was applied to predict $T_{m r t}$ at the Courtyard Library Courtyard at five-min intervals. A visualization of results is shown in Fig. 5. Point values of $T_{m r t}$ were extracted from CityComfort+ simulation at the grids where the four sensors were located and were to be compared with the field data. Surface temperatures were also calculated for the four facades and the ground. Inputs for

\footnotetext{
${ }^{2}$ On January 15, the wind speed was recorded at the west sensor location using Hobo anemometer (SWCA-M003) at three-second interval and averaged for every five min. The data was linearly corrected at three other locations based on a steady-state CFD test; On March 21, wind speed from nearby Harvard Arboretum weather station (KMAJAMAI4) was used and linearly corrected at four sensor locations. On August 23, localized wind speed was measured on the library roof top (S-WCA-M003) and at east, north, and west sensor locations (Rainwise). The speed at the south sensor is linearly corrected using roof-top measurement.
} 
CityComfort+ simulation included the 3-D urban model provided by the Boston Redevelopment Authority (BRA, 2012). Assumptions on material thermal properties were provided in Table 4.

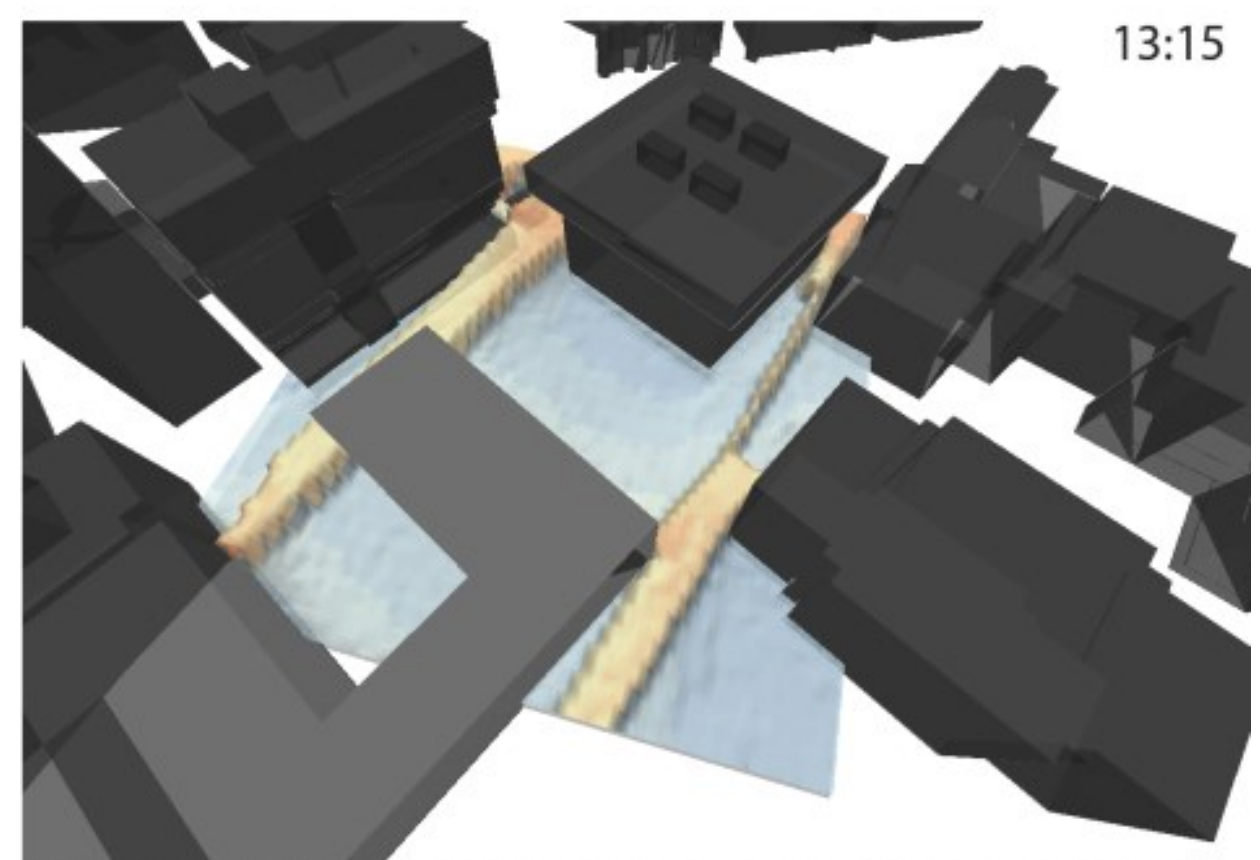

Mean Radiant Temperature at Countway Library, Harvard University, Boston, MA Janurary 15, 2012

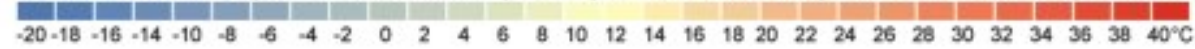

Fig. 5. Simulation of $\mathrm{T}_{\mathrm{mrt}}$ at the Countway Library Courtyard

Table 4. Assumptions used in CityComfort+ Simulation

\begin{tabular}{|c|c|c|c|}
\hline \multicolumn{2}{|l|}{ Material Properties } & \multicolumn{2}{|l|}{ Thermal Properties } \\
\hline Surface Material & Granite / Concrete & $A_{1}$ : Albedo of surface material & 0.35 \\
\hline$\rho_{\mathrm{m}}$ : Material Density & $2700 \mathrm{~kg} / \mathrm{m}^{3}$ & $\varepsilon$ : Emissivity & 0.95 \\
\hline$D_{m}$ Surface Depth & $0.2 \mathrm{~m}$ (8 inch) & $\mathrm{C}_{\mathrm{m}}$ : Heat Capacity Granite/Soil & $750 \mathrm{~J} / \mathrm{kg}^{\circ} \mathrm{C}$ \\
\hline $\mathrm{T}_{\mathrm{i}}$ : Internal Temp. (Building) & $22{ }^{\circ} \mathrm{C}$ & $\mathrm{h}_{\mathrm{a}}$ : Convective Coefficient & $15 \mathrm{~W} / \mathrm{m}^{2}{ }^{\circ} \mathrm{C}$ \\
\hline $\mathrm{T}_{\mathrm{i}}$ : Internal Temp. (Ground) & $10^{\circ} \mathrm{C}$ (Boston) & U: Thermal Conductivity (Wall) & $0.6 \mathrm{~W} / \mathrm{m}^{2}{ }^{\circ} \mathrm{C}$ \\
\hline $\mathrm{dt}$ : Time step & 300 seconds & U: Thermal Conductivity (Ground) & $0.6 \mathrm{~W} / \mathrm{m}^{2}{ }^{\circ} \mathrm{C}$ \\
\hline$\sigma:$ Stephan-Boltzmann's constant & $5.67 \times 10^{-8} \mathrm{~W} / \mathrm{m}^{2} \mathrm{~K}^{4}$ & $\mathrm{~T}_{0:}$ Initial Temperature & $\mathrm{T}_{\mathrm{a}}-3.4{ }^{\circ} \mathrm{C}$ \\
\hline
\end{tabular}

\section{Evaluation and discussion}


CityComfort+'s performance was evaluated by comparing simulated $\mathrm{T}_{\mathrm{mrt}}$ and surface temperature with measurement data. A sensitivity analysis was also performed to test the model response to changes in material emissivity, thermal massing, albedo, and building internal temperature.

\subsection{Evaluation of $T_{\text {mrt }}$}

Fig. 6, Fig. 7, and Fig.8 compare simulated and measured $T_{\text {mrt }}$ at four sensor locations over the three field study days. CityComfort+ performed well and its results agreed closely to the spatial-temporal variation of measured $\mathrm{T}_{\text {mrt }}$. Statistical analysis on the 30-min time-step results show a correlation $r$ of 0.97 and RMSE of $4.76{ }^{\circ} \mathrm{C}$ (Table 5). Differences between simulated and measured $\mathrm{T}_{\text {mrt }}$ are normally distributed (Fig. 9) with a mean difference of $-0.01^{\circ} \mathrm{C}$ and a standard deviation of $4.78^{\circ} \mathrm{C}$.

Table 5. RMSE between predicted and measured $\mathrm{T}_{\mathrm{mrt}}$ on $30 \mathrm{~min}$. time-step by sensor location by season.

\begin{tabular}{lccccc} 
RMSE $\left({ }^{\circ} \mathrm{C}\right)$ & East sensor & $\begin{array}{c}\text { North } \\
\text { sensor }\end{array}$ & South sensor & $\begin{array}{c}\text { West } \\
\text { sensor }\end{array}$ & $\begin{array}{r}\text { All fou } \\
\text { sensors }\end{array}$ \\
\hline Jan. 15 & 3.65 & 5.42 & 5.39 & $\mathrm{~N}^{*} \mathrm{~A}^{*}$ & 4.94 \\
Mar.21 & 3.56 & 4.58 & 2.79 & 3.28 & 3.61 \\
Aug.23 & 3.53 & 6.61 & 3.92 & 7.11 & 5.52 \\
All dates & 3.57 & 5.65 & 4.05 & 5.61 & 4.76
\end{tabular}

${ }^{*}$ No grey globe thermometer was presented at the west sensor location on Jan.15.Instead, a $150 \mathrm{~mm}$ black globe thermometer was placed there to evaluate the results of grey globe thermometers.

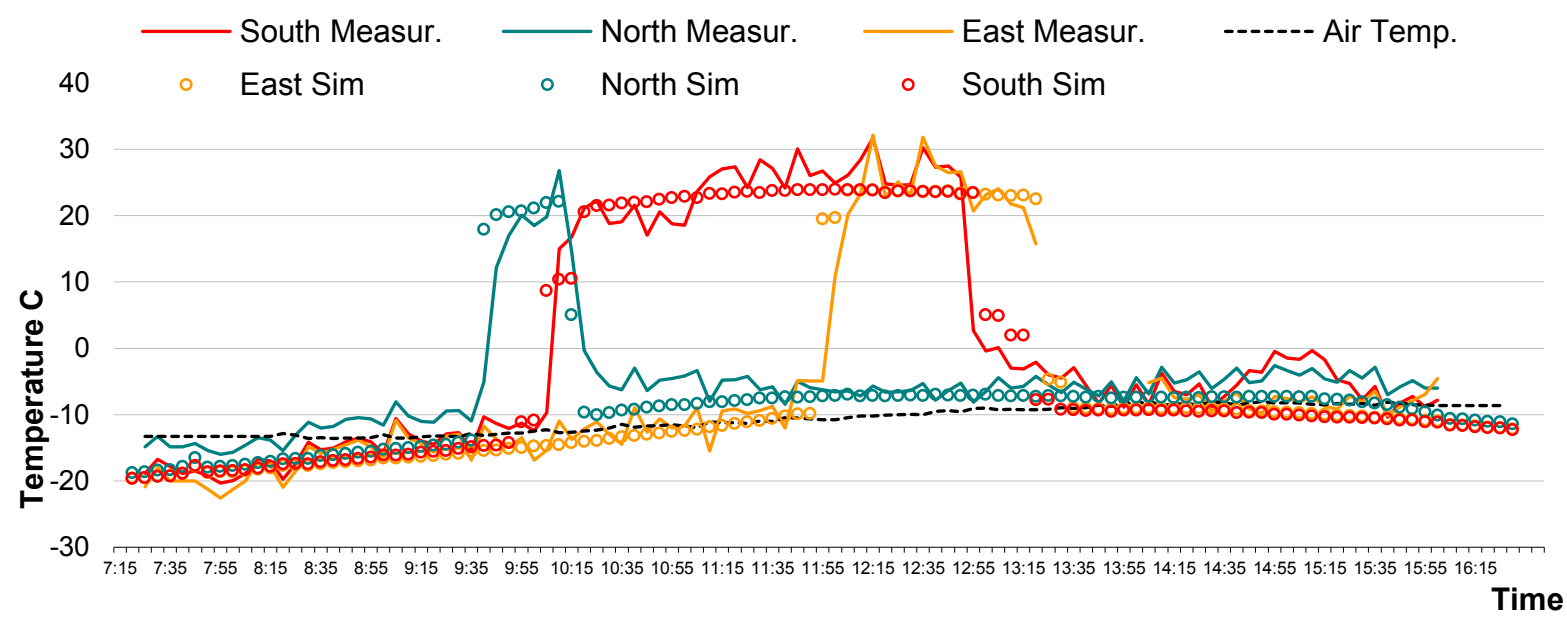

Fig. 6. Simulated and Measured $\mathrm{T}_{\mathrm{mrt}}$ at 5-min time-step on January 15, 2012 (clear sky) 


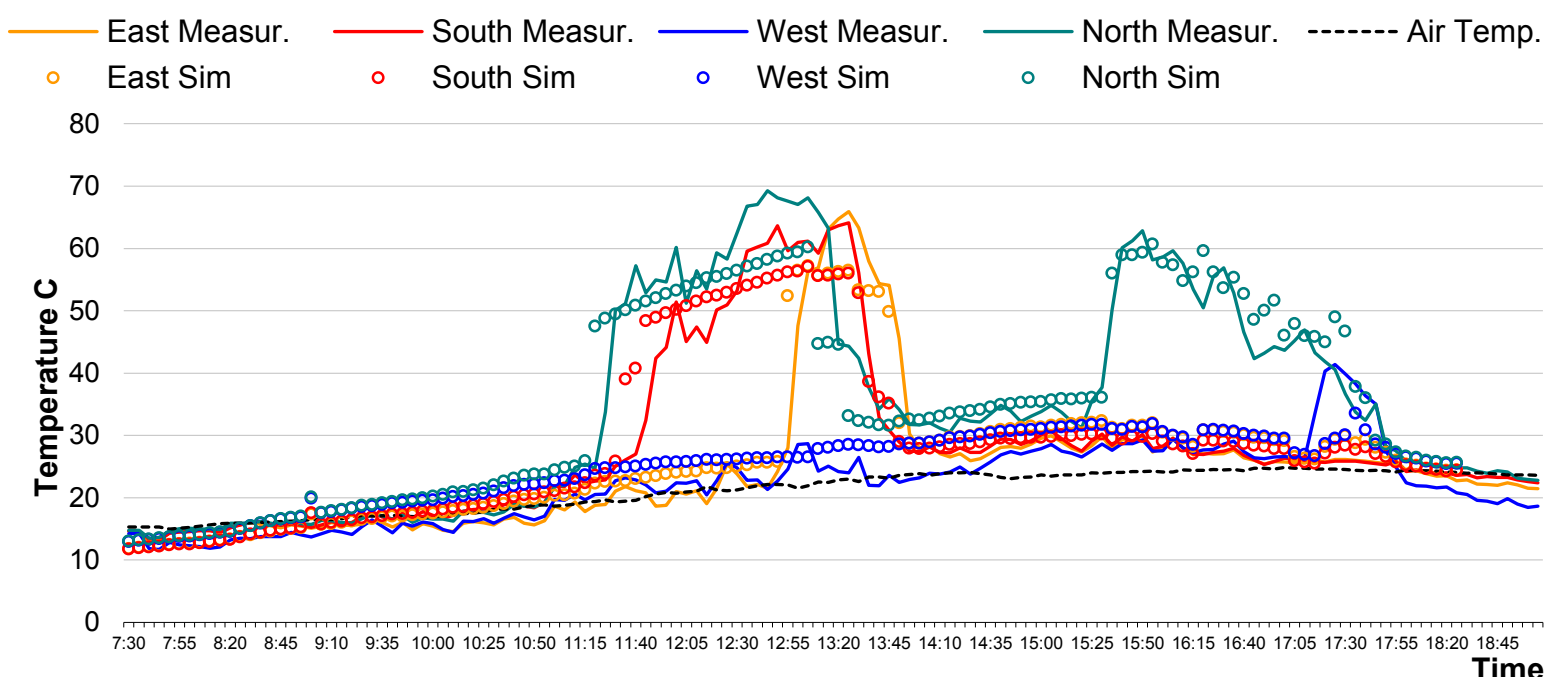

Fig. 7. Simulated and Measured $\mathrm{T}_{\mathrm{mrt}}$ at 5-min time-step on March 21, 2012 (clear sky)

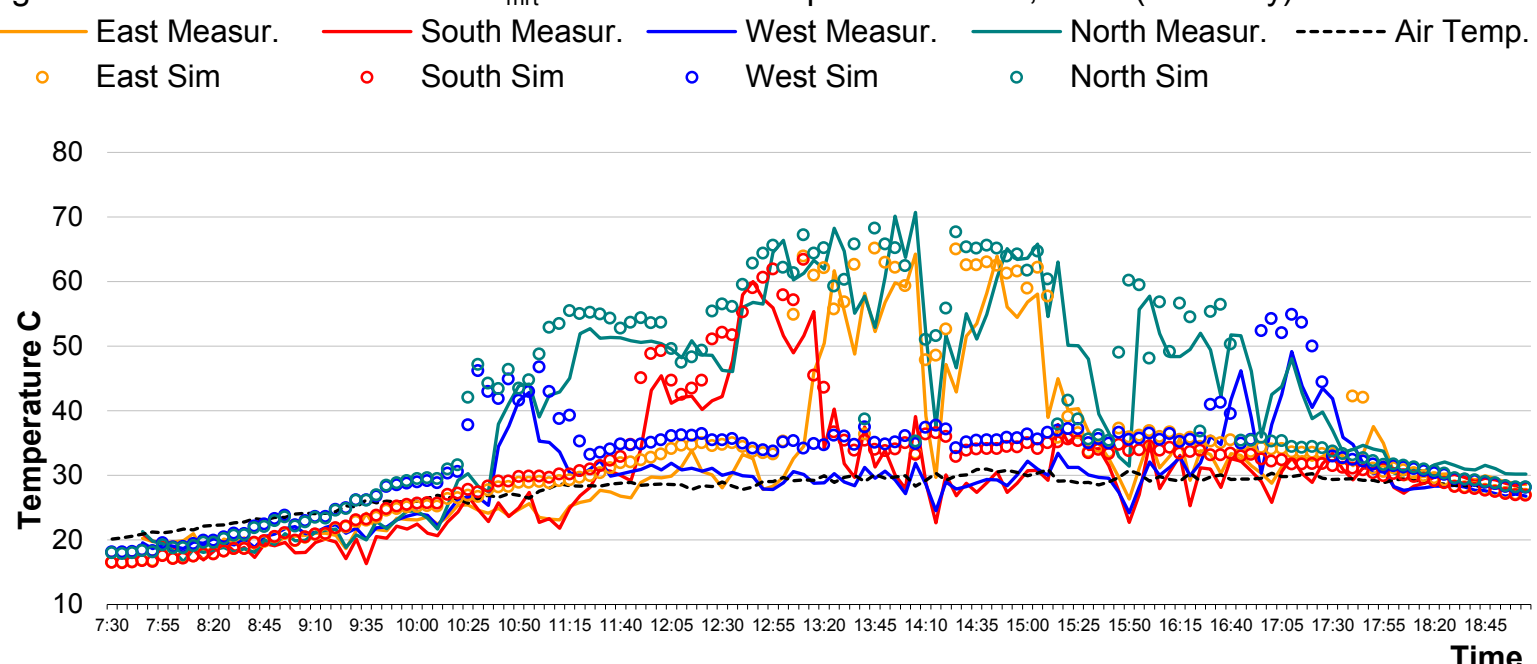

Fig. 8. Simulated and Measured $T_{\text {mrt }}$ at 5-min time-step on August 23, 2012 (cloudy/clear sky)

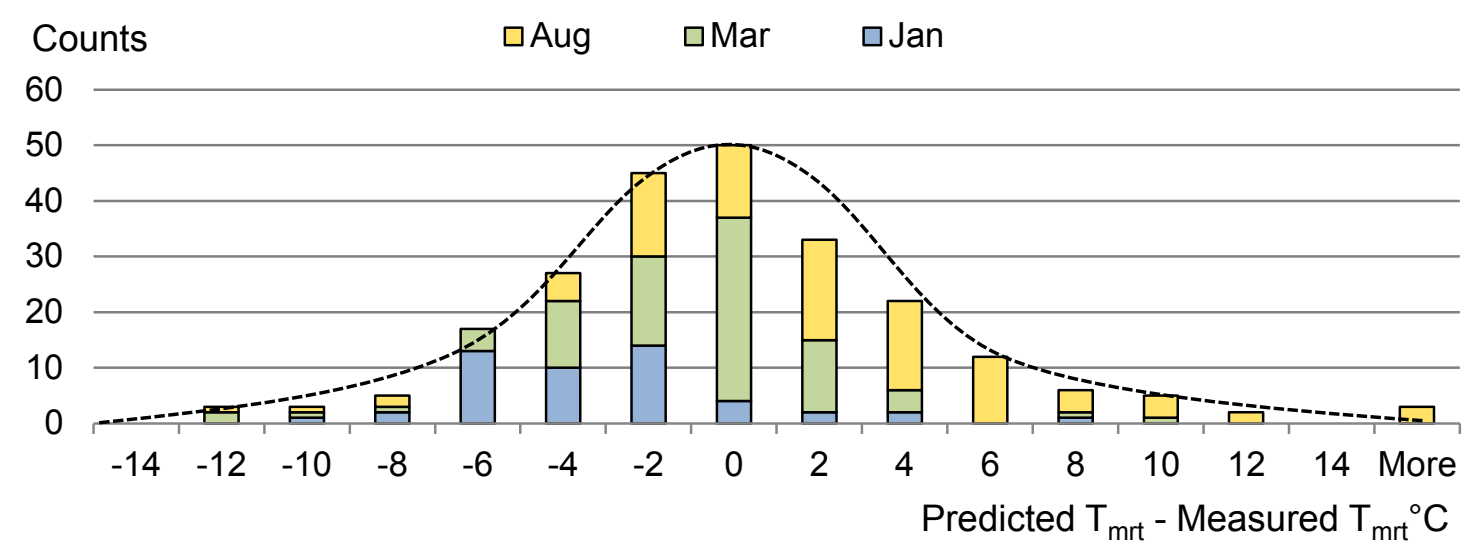

Fig. 9. Distribution of differences between predicted and measured $T_{m r t}$ at 30-min time-step 
The differences between predicted $T_{m r t}$ and measurement data exposed three limitations of this study: 1) instrument accuracy, 2) grey ball response time, and 3) inherent uncertainties embedded in CityComfort+. The first limitation was instrument errors associated with the sensors in use. Labeled accuracy for the temperature sensor (S-THB-M002) is $\pm 0.2^{\circ} \mathrm{C}$; the accuracy for anemometer (S-WCA_M003) is $\pm 0.5 \mathrm{~m} / \mathrm{s}$. Aggregate error for $T_{\text {mrt }}$, calculated using Formula 11 at 30-min intervals during the three days of field studies, was $\pm 3.90^{\circ} \mathrm{C}$. This value is close to the standard deviation of the differences between predicted and measured $\mathrm{T}_{\text {mrt }}$ of $4.78^{\circ} \mathrm{C}$.

A second limitation was grey ball response time, the delay in changes of measured $T_{\text {mrt }}$ caused by the thermal inertial of the thermometers. Response time resulted in a scattering effect which was more visible on August 23 under cloudy sky conditions when sensors were frequently transitioning between sunlight and shadow. By changing the simulation time-step from $5 \mathrm{~min}$ to $30 \mathrm{~min}$, the scattering was reduced (Fig. 10 lower left); it could be further reduced by using a 30-min mean on both 5-min time-step simulation results and measurement data (Fig. 10 lower right).

A third limitation was related to assumptions embedded in CityComfort's algorithm. Currently, long-wave radiation from windows and glass doors cannot be modeled effectively. It was hypothesized that building glazing is a contributing factor to the underestimation of $T_{m r t}$ in January and overestimation of $T_{m r t}$ in March and August; since windows, although small at the Countway Library courtyard, could have lower insulation value therefore is more likely to be affected by the indoor environment compared with external walls. This uncertainty might reduce the performance of CityComfort+ in places where large areas of glass curtain walls are present. Another uncertainty for CityComfort+ is its simplified method to estimate view factors for sunlit and shaded surfaces. The magnitude of such uncertainty, given by a hand calculation in Appendix A, appeared to be rather small -- about $1.2^{\circ} \mathrm{C}$ assuming the courtyard has two facades heated by the sun. This difference is insignificant compared with other sources of uncertainties, such as assumptions about material thermal properties. In other words, the challenge for CityComfort+ time and spatially resolved performance will be the difficulty of specifying the physical details of the urban environment. 


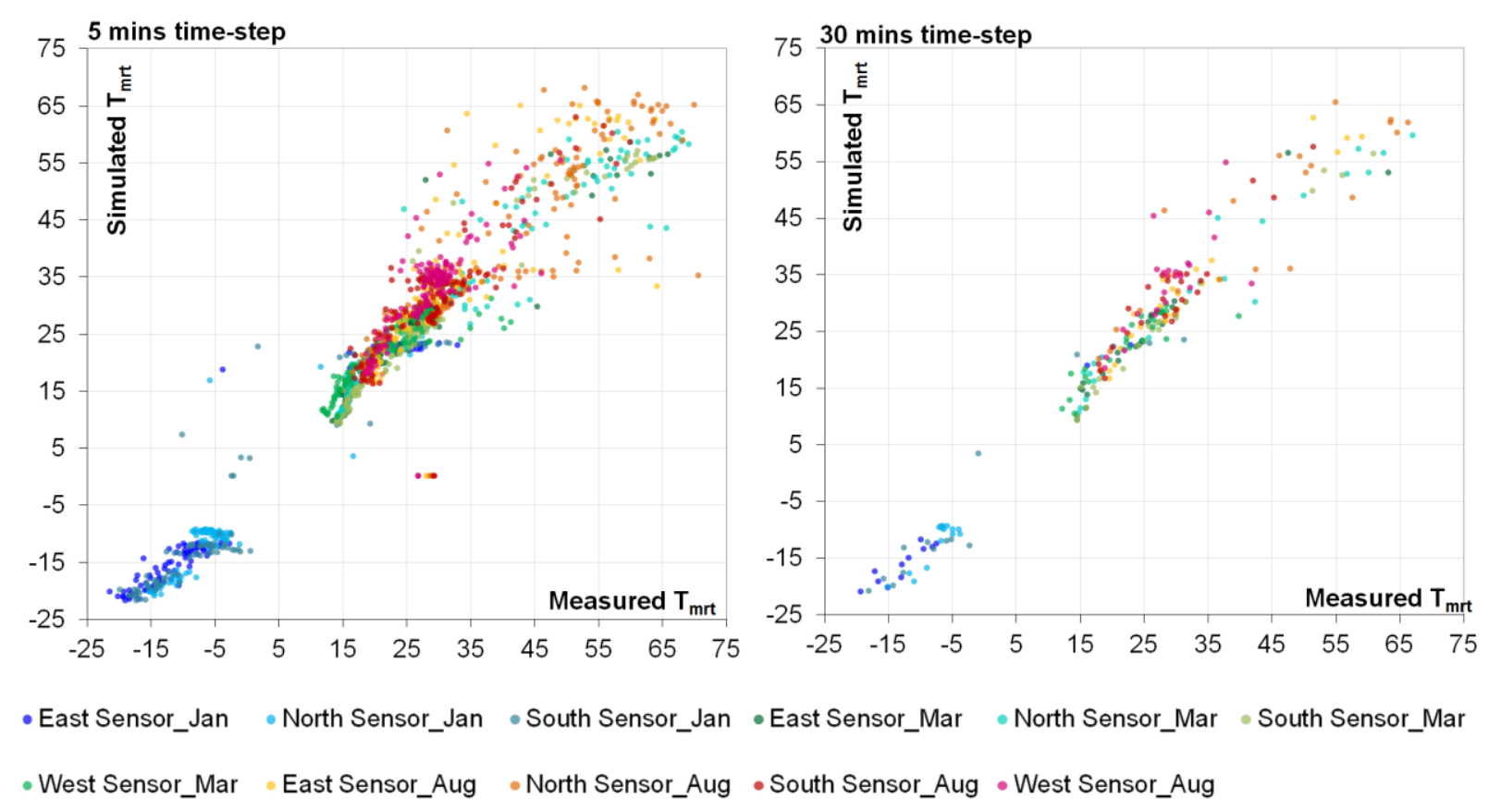

Fig. 10. Scatterplot of simulated $\mathrm{T}_{\mathrm{mrt}}$ and measured $\mathrm{T}_{\mathrm{mrt}}$ at 5-min time-step (upper), 30-min time-step (lower left), and 30-min average based on 5-min time-step (lower right)

\subsection{Evaluation of surface temperature}

To assess the long-wave radiation emitted from urban surfaces, it is necessary to know the mean surface temperature $\left(\bar{T}_{s v}\right)$, which is hypothetical value defined as the average temperature of each small surface weighted by their view factors to a person.

Observed $\bar{T}_{s v}$ at the center of the Countway Library courtyard was computed using Formula 12 below. Mean façade temperatures were measured regularly using infrared photography (Fig. 11). In a real setting, temperature on the same building façade often varies because of material, shadow, or heat transfer. To account for this variability, average temperature of a wall or ground was calculated using the average of four point-measurements using the infrared camera. The mean view factors of four building façades as well as the ground from four sensor locations were manually calculated based on the 3-D site model.

Formula 12

$$
\bar{T}_{\text {sv }}=\bar{T}_{\text {east }} \cdot \bar{F}_{\text {east }}+\bar{T}_{\text {north }} \cdot \bar{F}_{\text {north }}+\bar{T}_{\text {west }} \cdot \bar{F}_{\text {west }}+\bar{T}_{\text {south }} \cdot \bar{F}_{\text {south }}+\bar{T}_{\text {ground }} \cdot \bar{F}_{\text {ground }}
$$


$\bar{T}_{n} \quad=$ Mean façade temperature $\left({ }^{\circ} \mathrm{C}\right)$

$\bar{F}_{n} \quad=$ Mean view factor (Ratio, $\left.0 \sim 1\right)$

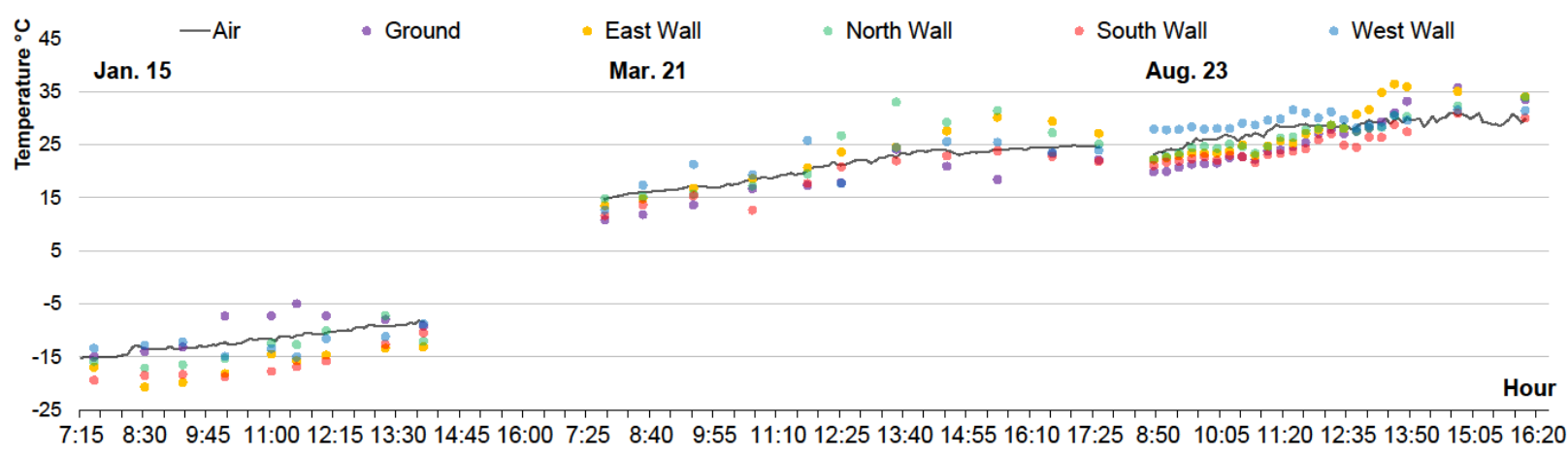

Fig. 11. Mean surface temperature at building walls and ground observed at Countway Library courtyard.

Simulated $\bar{T}_{s v}$ was computed using CityComfort+. Simulation results included surface temperatures and view factors of four groups of surfaces including sunlit wall, shaded wall, sunlit ground, and shaded ground. Simulated $\bar{T}_{s v}$ can be calculated using the following formula:

Formula 13

$\bar{T}_{s v}=\bar{T}_{s l w} \cdot F_{s l w}+\bar{T}_{s d w} \cdot F_{s d w}+\bar{T}_{s \mathrm{lg}} \cdot F_{s \mathrm{lg}}+\bar{T}_{s d g} \cdot F_{s d g}$

$\bar{T}_{s l w} \quad=$ Mean surface temperature of sunlit wall $\left({ }^{\circ} \mathrm{C}\right)$

$F_{s l w} \quad=$ View factor of sunlit wall $($ ratio, $0 \sim 1)$

$\bar{T}_{s d w} \quad=$ Mean surface temperature of shaded wall $\left({ }^{\circ} \mathrm{C}\right)$

$F_{s d w} \quad=$ View factor of shaded wall (ratio, 0 1)

$\bar{T}_{s \mathrm{~g}} \quad=$ Mean surface temperature of sunlit ground $\left({ }^{\circ} \mathrm{C}\right)$

$F_{s \mathrm{~g}} \quad=$ View factor of sunlit ground (ratio, 0 1)

$\bar{T}_{s d g} \quad=$ Mean surface temperature of shaded ground $\left({ }^{\circ} \mathrm{C}\right)$

$F_{s d g} \quad=$ View factor of shaded ground (ratio, 0 1) 
Fig. 12 compares observed and simulated $\bar{T}_{s v}$ at the center of the Countway Library courtyard. The two matched closely with a correlation $r$ of 0.996 and a RMSE of $1.54{ }^{\circ} \mathrm{C}$. The RMSE value falls within the range of labeled instrument accuracy of $\pm 2{ }^{\circ} \mathrm{C}$ (Fig.13).

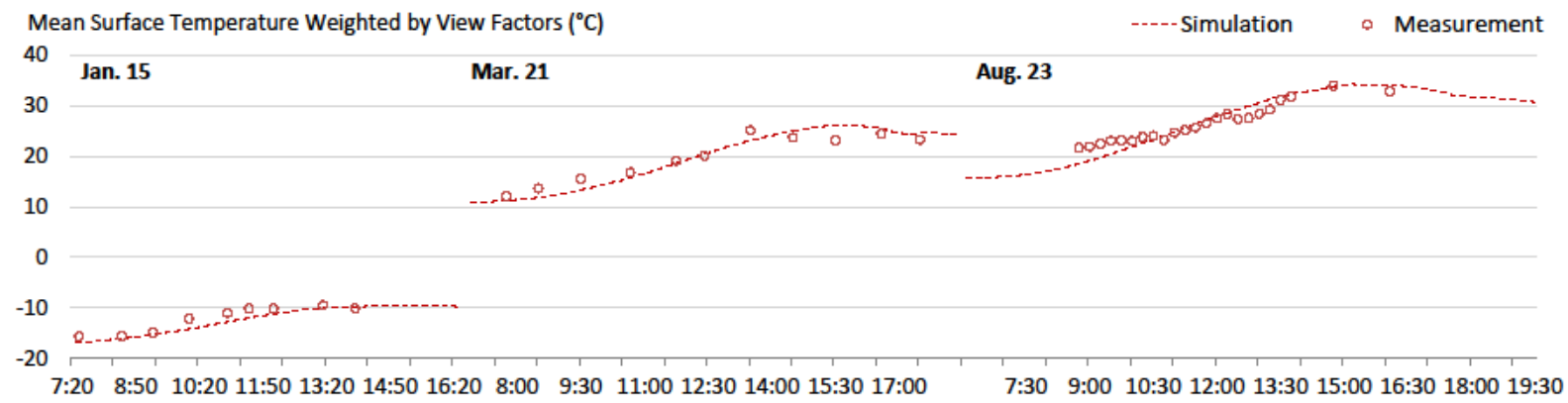

Fig. 12 Simulated and measured mean surface temperature weighted by view factors at the center of Countway Library courtyard

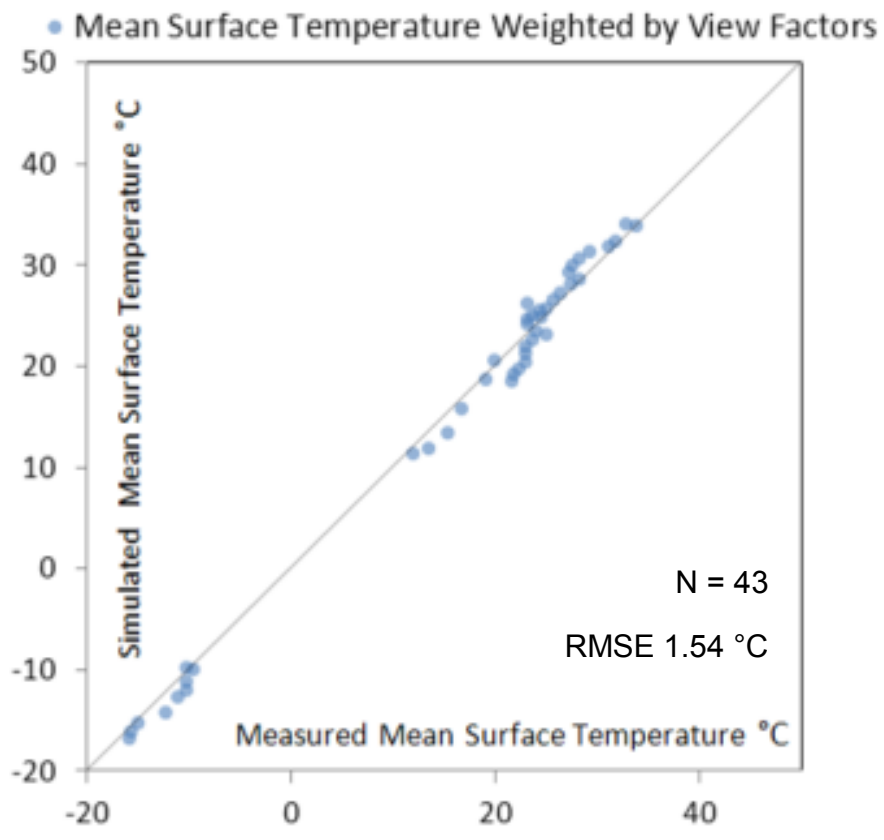

Fig. 13. Measured and Simulated Mean Surface Temperature Weighted by View Factor (MST_VF)

\subsection{Sensitivity}

CityComfort+ simulation is based a series of assumptions on material thermal properties as well as site conditions. It is important to test model responses by changing these assumptions individually. This 
section test four simulation scenarios where changes were made on the following variables: 1) emissivity 2) thermal massing, 3) albedo, and 4) building internal temperature. The ranges of change are based on a variety of commonly available building materials. The responses of simulated $T_{\text {mrt }}$ and mean surface temperature $\bar{T}_{s v}$ are shown in Fig. 14 and Fig. 15. Surface emissivity and thermal massing have major influences on $\mathrm{T}_{\text {mrt }}$ responses. Surface albedo has a major influence on $\bar{T}_{s v}$ response.

If surface emissivity changes from 0.95 to 0.75 , equivalent of replace granite walls with fireclay bricks, simulated $\mathrm{T}_{\text {mrt }}$ will decrease by $3.82{ }^{\circ} \mathrm{C}$ while mean surface temperature $\bar{T}_{s v}$ will increase by $0.17^{\circ} \mathrm{C}$ (Fig. 15). This effect can be explained by reductions in long-wave radiative emissions from surfaces.

Thermal massing has a major influence especially on peak-time $T_{\text {mrt }}$ and surface temperature. A reduction of the heat capacity of surface structure by $78 \%{ }^{3}$ results in an increase of $4.63{ }^{\circ} \mathrm{C}$ in $\mathrm{T}_{\text {mrt }}$ and up to $8{ }^{\circ} \mathrm{C}$ degree rise in $\bar{T}_{s v}$. A reduction of heat capacity to zero results in a rise of $6.23{ }^{\circ} \mathrm{C}$ in $\mathrm{T}_{\mathrm{mrt}}$ and up to $15^{\circ} \mathrm{C}$ in $\bar{T}_{s v}$.

Surface albedo has a small influence on simulated $\mathrm{T}_{\mathrm{mrt}}$, although it significantly affects $\bar{T}_{s v}$. A reduction of surface albedo from 0.35 to 0.2 , equivalent to replacing granite tile with brick veneer, results in a small increase of $0.24{ }^{\circ} \mathrm{C}$ in $\mathrm{T}_{\mathrm{mrt}}$. Meanwhile, predicted $\bar{T}_{s v}$ will increase by $1.25^{\circ} \mathrm{C}$ with higher peak values in summer when solar angles are high (Fig. 15).

The internal temperature of buildings has a negligible influence on both $\mathrm{T}_{\mathrm{mrt}}$ and surface temperature. By changing the internal temperature from $22^{\circ} \mathrm{C}$ to $15^{\circ} \mathrm{C}$, CityComfort+ predicts a miniscule decrease of

\footnotetext{
${ }^{3}$ The original surface heat capacity was set to $405,000 \mathrm{~J} /{ }^{\circ} \mathrm{C} \mathrm{m}{ }^{2}$, equivalent to a $20 \mathrm{~cm}$ thick granite wall. The reduced-thermal-massing scenario assumes a surface heat capacity of $90,000 \mathrm{~J} /{ }^{\circ} \mathrm{C} \mathrm{m}$, equivalent of $20 \mathrm{~cm}$ solid wood wall. Specific heat and density data are derived from Source: Engineering ToolBox,
} 2013. 
$0.03^{\circ} \mathrm{C}$ in $\mathrm{T}_{\mathrm{mrt}}$ and a $0.05^{\circ} \mathrm{C}$ reduction in mean surface temperature. In cities where building walls are well insulated, temperatures inside buildings are less likely to affect $\mathrm{T}_{\mathrm{mrt}}$ in the outdoor environments.

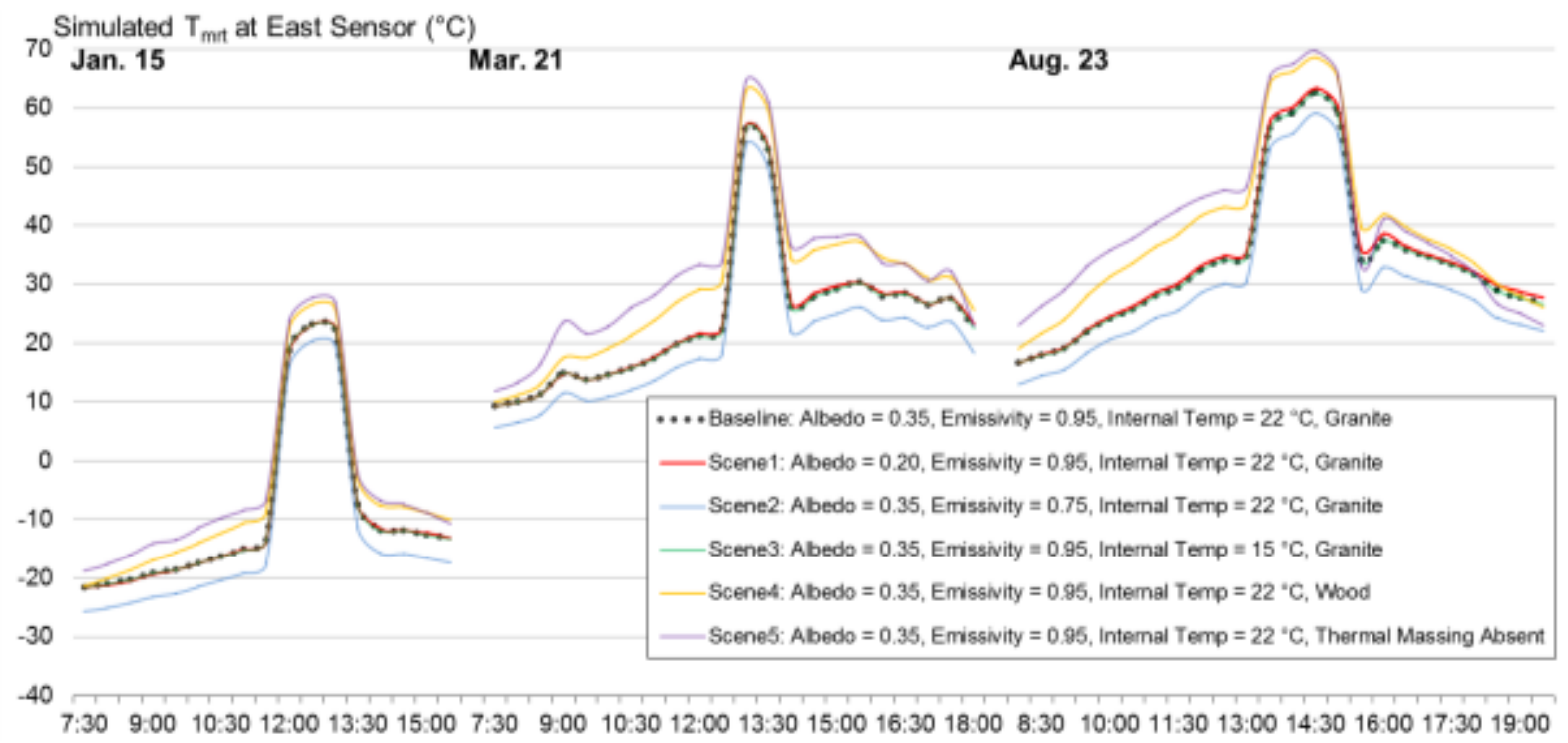

Fig. 14. Predicted $T_{\text {mrt }}$ at east sensor under the baseline and five alternative scenarios. $T_{m r t}$ is sensitive towards changes in material thermal massing and emissivity. It is less sensitive towards changes in albedo and building internal temperature.

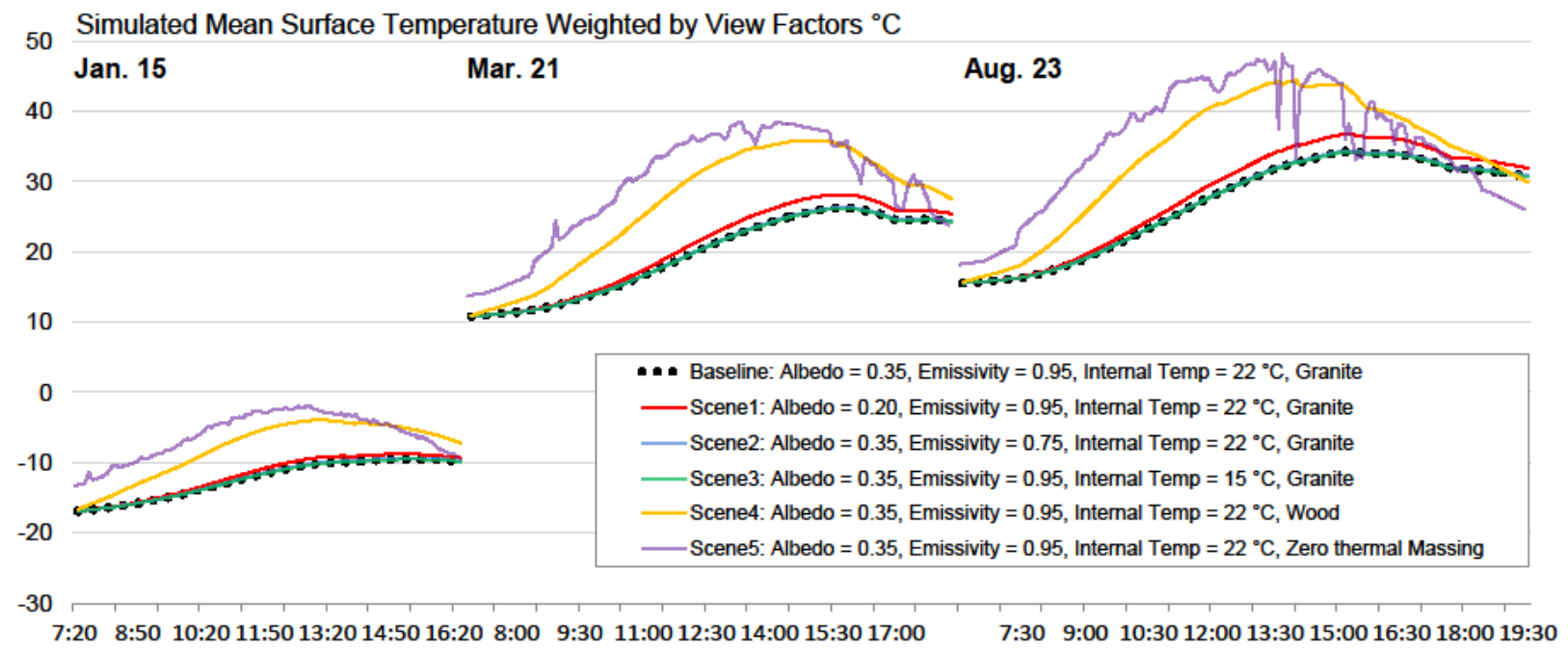

Fig. 15. Predicted mean surface temperature $\bar{T}_{s v}$ under the baseline and five alternative scenarios. $\bar{T}_{s v}$ is sensitive towards changes in albedo and thermal massing effects. It is less sensitive towards changes in emissivity and building internal temperature.

\section{Conclusion}


The CityComfort+ model simulates the spatial variation of outdoor $\mathrm{T}_{\mathrm{mrt}}$ in complex built environment. This method was evaluated using measurement data obtained from field studies in Boston under winter, spring, and summer weather conditions. CityComfort+ simulation yielded good agreement with measured $\mathrm{T}_{\text {mrt }}$ under the study site conditions, with a correlation r of 0.97 and root mean square error (RMSE) of $4.76{ }^{\circ} \mathrm{C}$, over 33 hours of evaluation.

CityComfort+ is applicable to assessing the thermal comfort of urban landscapes and other public places. $\mathrm{T}_{\mathrm{mrt}}$ can be effectively controlled in an outdoor built environment by installing shading devices and changing surface materials. Sensitivity analysis included in this paper showed that the choice of material, such as thermal massing and emissivity has significant impact on outdoor $\mathrm{T}_{\mathrm{mrt}}$, an observation that can inform the design of public open spaces and the layout of building insulation.

CityComfort+ is still under development. The methods to model surface temperature can be further improved. Additional algorithms will be included that takes into account shading and evapotranspiration from vegetation. A next step is to compare its performance with existing methods, including Rayman (Matzarakis et al., 2010), ENVI-met (Bruse, 2009), and SOLWEIG (Lindberg et al, 2008). A future goal is to enable CityComfort+ to predict outdoor thermal comfort in urban environments. To this end, additional algorithms are needed to estimate localized wind speed, air temperature, humidity, human body heat transfer and thermal regulation.

\section{Acknowledgements}

The study is partially sponsored by the EFRI-1038264 award from the National Science Foundation (NSF), Division of Emerging Frontiers in Research and Innovation (EFRI). Special thanks to Professor

Christoph F. Reinhart of MIT for his advices and for offering us to use the Hobo weather station. Special thanks extended to Professor Jelena Srebric of the University of Maryland, who lend us the Infrared camera during the field measurement.

\section{Appendix A}


Appendix A explains the rationales behind Formula 11, which converts measured globe temperature into $\mathrm{T}_{\mathrm{mrt}}$ by adjusting for convective heat exchanges during the field studies. For a globe thermometer in energy equilibrium, its radiant energy gains (loss) equal convective energy loss (gains) for each globe.

Formula A.1

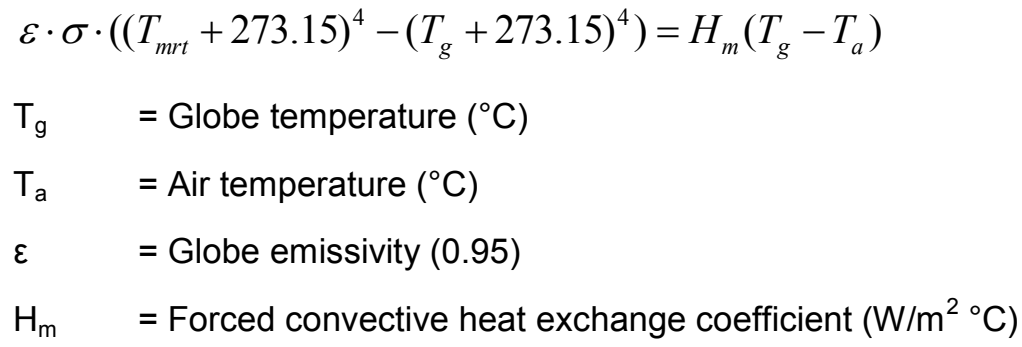

The forced convective heat transfer coefficient $\mathrm{H}_{\mathrm{m}}$ is a function of wind speed, air density, air conductivity coefficient, air viscosity, and globe diameter. $\mathrm{H}_{m}$ is empirically derived from experiments (Kuehn et al., 1970). Kuehn's original formula is converted into SI units and expressed in Formula A.2.

$$
\begin{aligned}
& \text { Formula A.2 } H_{m}=6.02 \cdot V_{a}^{0.58} \cdot D^{-0.42} \\
& \begin{array}{ll}
\mathrm{V}_{\mathrm{a}} \quad=\text { Wind speed }(\mathrm{m} / \mathrm{s}) \\
\mathrm{D} \quad=\text { Globe diameter }(\mathrm{m})
\end{array}
\end{aligned}
$$

Considering that Kuehn's formula was derived from indoor lab experiment, it is possible that the use of Formula 11 is subject to additional convective heat loss in the outdoor environment. To test the accuracy of $40 \mathrm{~mm}$ globe thermometers, two steps were taken in field studies. Firstly, a $150 \mathrm{~mm}$ (6-inch) black thermometer on Jan. 15, 2012 as a redundant experiment to evaluate results from $40 \mathrm{~mm}$ globe thermometers, knowing that a bigger globe size is expected to reduce the impact of convective heat loss thus improving the accuracy of the measurement (Figure A.1). Second, analysis is performed for the divergence between predicted and measured $T_{\text {mrt }}$ in relation to outdoor wind speed. Results from both steps suggested that the majority of the divergence between predicted and measured $T_{\text {mrt }}$ came from the simulation, not uncertainties of the $40 \mathrm{~mm}$ grey globe thermometers. 


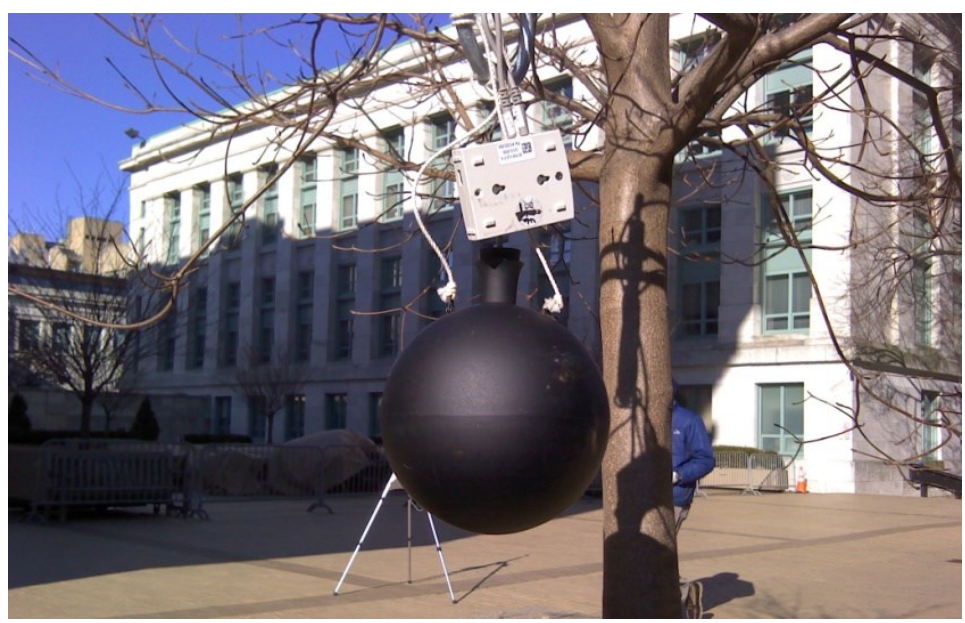

Figure A.1. The use of $150 \mathrm{~mm}$ (6-inch) black globe thermometer on Jan.15 2012 as a redundant experiment to evaluate the use of $40 \mathrm{~mm}$ grey globe thermometer. Photo taken Jan.15, 2012

In the first step, a $150 \mathrm{~mm}$ (6-inch) black globe thermometer was deployed on Jan.15 2012 in parallel to the use of grey globe thermometers. Started at the west sensor location, the black globe thermometer was later moved near the south sensor location under the direct sunlight after 11:15 that day. Measurement results using the $150 \mathrm{~mm}$ black globe thermometer, supposedly less vulnerable to convective heat loss, did not match better with the simulation result (Figure A.2). Measured $\mathrm{T}_{\text {mrt }}$ using the $150 \mathrm{~mm}$ black globe thermometer, again calculated using Formula 11 derived from Kuehn's study (Kuehn, L A.; Stubbs, R A. and Weaver, R S. Theory of the globe thermometer. Journal of Applied Physiology 29, 1970), was represented using the red line in Figure 2 below. Here, the use of Formula 11 can be justified because the range of wind speed measured on site was between 0.74 to $2.51 \mathrm{~m} / \mathrm{s}$ on the study day, within the wind speed range of 0.5 and $2.7 \mathrm{~m} / \mathrm{s}$ during Kuehn's original lab experiment. Predicted $\mathrm{T}_{\text {mrt }}$ for the $150 \mathrm{~mm}$ globe was presented in red dots. Measured $\mathrm{T}_{\mathrm{mrt}}$ using $40 \mathrm{~mm}$ grey globe thermometer was illustrated in the green line, and predicted $\mathrm{T}_{\text {mrt }}$ for this sensor was shown in green dots.

The divergences between predicted and measure $T_{\mathrm{mrt}}$ were comparable for $150 \mathrm{~mm}$ and $40 \mathrm{~mm}$ globe thermometers. This is to say, the bigger globe did not reduce the divergence significantly. Measured $T_{\mathrm{mrt}}$ using both large and small globes were consistently higher (up to $6^{\circ} \mathrm{C}$ ) than predicted under cold / shadowy conditions. However, the use of the $150 \mathrm{~mm}$ globe created another problem due to the instrument response time. Between 8:20 and 8:35, the west sensor location was exposed briefly under the morning sun, and there was a 15-min time lag of measured $T_{\text {mrt }}$ rise behind the predicted data (Figure 
2). The accuracy of building geometries might have contributed to the time lag aside from instrument response time, since a minor inaccuracy of the 3D building models can change the timing of shadows in simulation.

\section{Prediction and Measurement of $\mathrm{T}_{\text {mrt }}$ Using $150 \mathrm{~mm}$ Black Globe and $40 \mathrm{~mm}$ Grey Globe On Janrary 15, 2012}

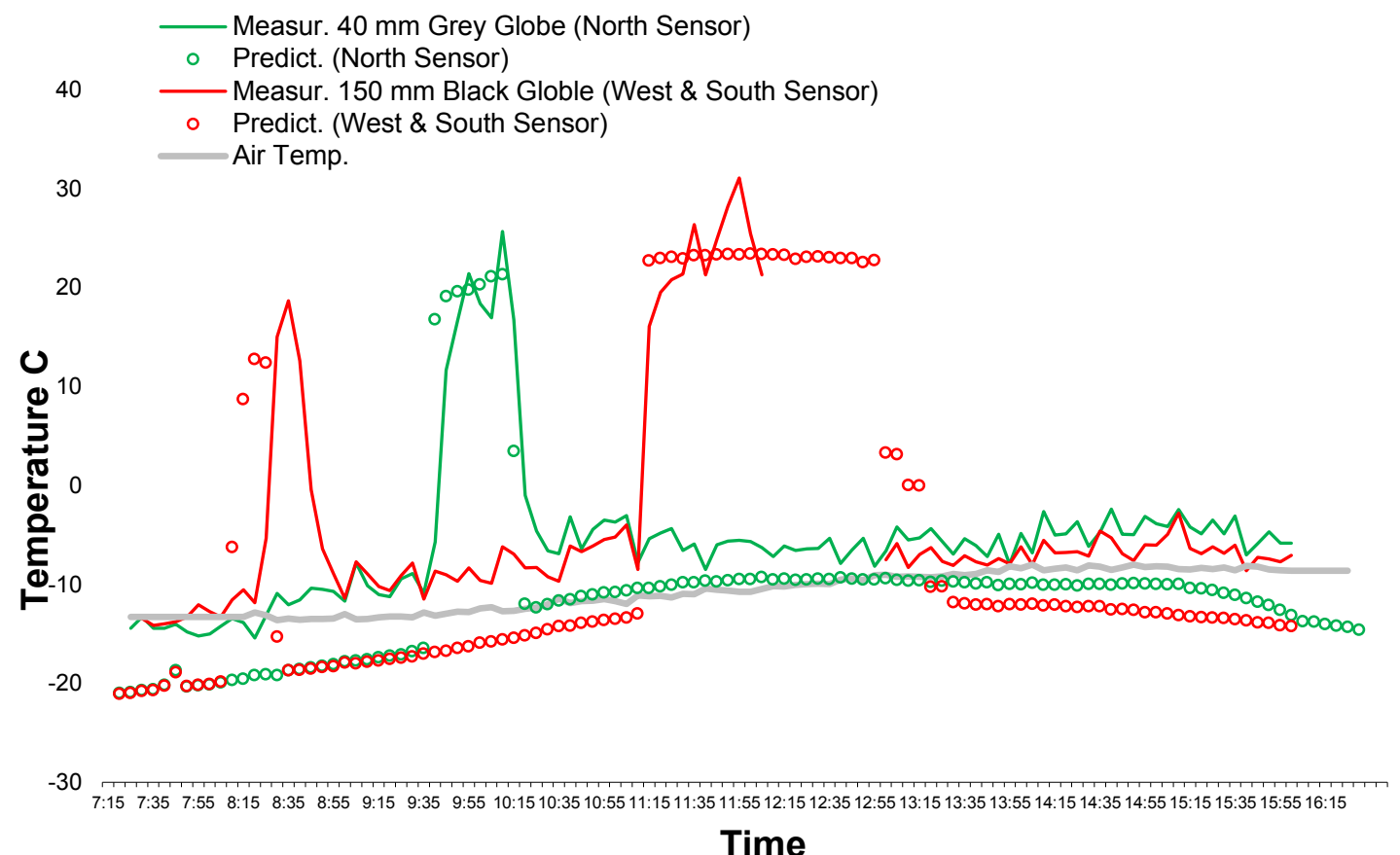

Figure A.2. Prediction and measurement of $T_{\text {mrt }}$ using $150 \mathrm{~mm}$ black globe and $40 \mathrm{~mm}$ grey globe on January 15,2012 . The redline represents measured $T_{\text {mrt }}$ using the $150 \mathrm{~mm}$ globe first at the west sensor location, and later moved to south sensor locations, with a few missing data between 12:15 - 12:55 when the instrument was brought off-site. The red dots represent simulated $T_{\text {mrt }}$ for the $150 \mathrm{~mm}$ globe. The green line represents measured $T_{\mathrm{mrt}}$ using the $50 \mathrm{~mm}$ globe at the north sensor location, with green dots showing prediction $\mathrm{T}_{\mathrm{mrt}}$ at the same location.

The second step is to map the correlation between the divergence (between measured and predicted $\mathrm{T}_{\mathrm{mrt}}$ using $40 \mathrm{~mm}$ grey globe thermometer in absolute value) and wind speed. Our hypothesis is that if convective heat loss due to outdoor wind is a major cause for these divergences, a strong correlation is expected between the two variables. Figure A.3 shows a weak correlation between these two variables with a correlation $r$ of 0.11 -- a low wind speed situation did not reduce the divergences between predicted and measured $T_{\text {mrt }}$, thus the majority of the divergence is likely coming from uncertainties of the simulation, not convective heat loss of the globe thermometer. 


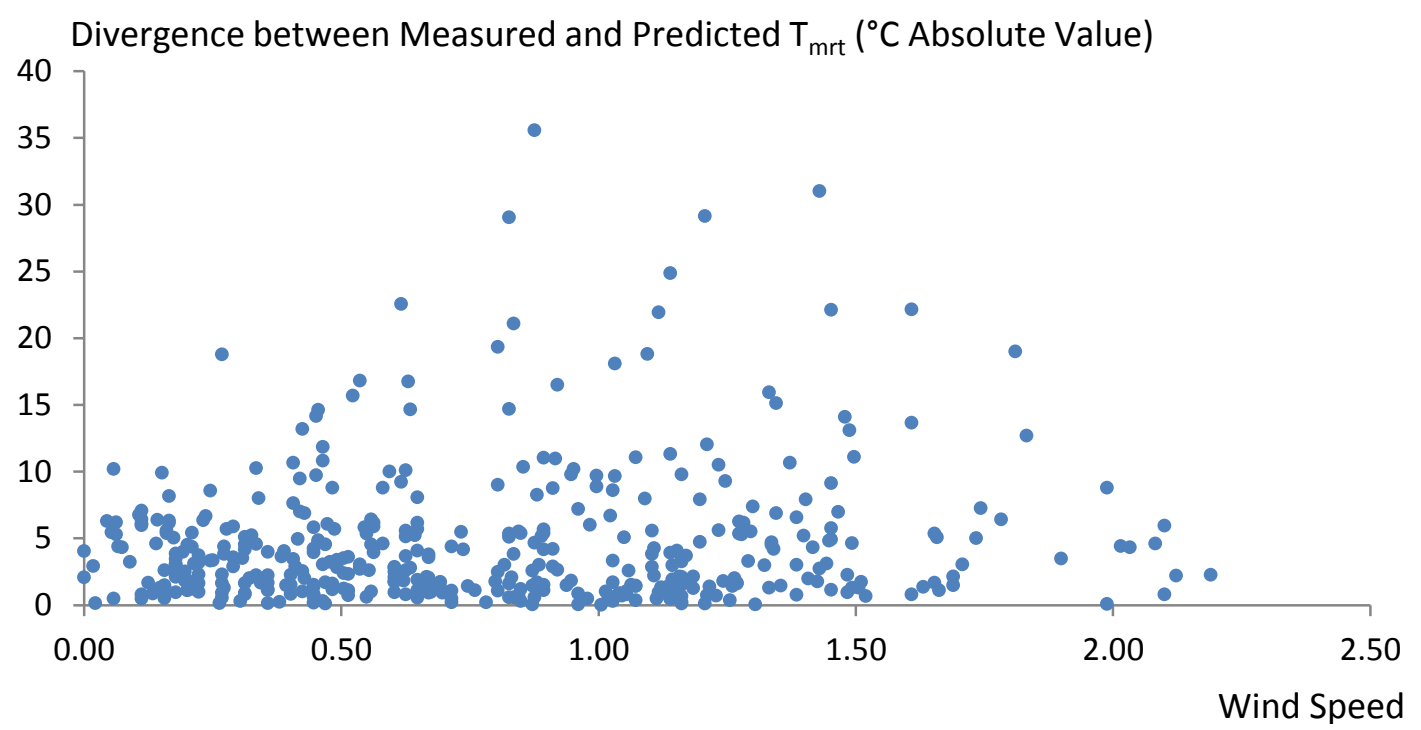

Figure A.3. Divergences between measured and predicted $T_{\text {mrt }}$ (in absolute value) in relation to wind speed in Aug.2012. A weak correlation between the two variables (correlation $r=0.11$ ) was observed.

\section{Appendix B}

To create scene files for RADIANCE software, urban geometries are first processed in Rhinoceros, a popular software package that takes in vector-based 3-D model formats such as 3DM, DWG, DXF, 3DS, or STL. Once the geometries are imported in Rhinoceros, a sensor grid is created using DIVA-for-Rhino plug-in to captures downward solar irradiance at $1.5 \mathrm{~m}$ above ground, the average height where radiation is sensed by pedestrians. A list of material properties are assigned to each surface in DIVA-for-Rhino plugin. The next step is to generate a sky model that describes parameters of the sun and the distribution of luminance on the sky dome. The input data are direct normal irradiance (DNI), diffuse horizontal irradiance (DHI), site geographic coordinates and time zone. In RADIANCE, the distribution of luminance on the sky dome is estimated using Perez formula (Perez, 1988).

For each time-step and each sensor location, irradiance is calculated twice using the 'rtrace' command in RADIANCE. The first step is to calculate direct solar irradiance with the value of 'ambient bounce' set to zero $(a b=0)$, accounting for radiation directly from the sun. The second step calculates irradiance from direct, diffused, and reflected sunlight, setting the value of ambient bounce to two (ab=2), allowing light to bounce off other surfaces twice. The intensities of diffused and reflected sunlight are computed by subtracting the first step result from the second. The workflow is automated using a script written in 
Python programming language. The results are direct and indirect solar irradiance at the center of each grid cell in ASCII format, which can be later mapped as raster layers in ArcMap 10. To adjust for Daylight Savings Time which is observed in the US, the meridian input were manually shifted 15 degrees eastward.

\section{References}

[1]. Lindberg, F.; Holmer, B.; Thorsson,S.. (2008) SOLWEIG 1.0-Modeling spatial variations of 3-D radiant fluxes and mean radiant temperature in complex urban settings. International Journal of Biometeorology 52

[2]. International Organization for Standardization (ISO).(1998) Ergonomics of the thermal environment - Instrument for measuring physical quantities. Geneva, Switzerland. ISO 7726

[3]. Folk, G. (1974) Texbook of Environmental Physilogy. Lea \& Febiger, Philadelphia

[4]. Whyte, W. (1980) The Social Life of Small Urban Space, Project for Public Spaces Inc. New York

[5]. Nikolopoulou, M.; Lykoudis, S. (2006) Thermal comfort in outdoor urban spaces: Analysis across different European countries. Building and Environment, 41 (11)

[6]. Intergovernmental Panel on Climate Change (IPCC) (2013) Climate Change 2013: The Physical Science Basis. Available at http://www.ipcc.ch/report/ar5/wg1/\#.UlgAQ1CkoXc

[7]. Matzarakis, A.; Rutz, F.; Mayer, H.. (2010) Modelling radiation fluxes in simple and complex environments: basics of the RayMan model. International Journal of Biometeorology 54: pp.131139

[8]. Bruse, M. (2009) ENVI-met V3.1 - A three dimensional microclimate model. Ruhr University at Bochum, Geographischer Institute, Geomatik, Available at http://www.envi-met.com

[9]. Thorsson,S; Lindberg, F.; Eliasson, I.; Holmer, B.(2007) Different methods for estimating the mean radiant temperature in an outdoor urban setting. International Journal of Climatology, 27, pp19831993 Retrieved May 2012 
[10]. Ali Toudert, F.(2005) Dependence of Outdoor Thermal Comforton Street Design in Hot and Dry Climate. Ph.D. Dissertation, University of Freiburg

[11]. Lin, B.; Zhu, Y.; Li, X.; Qin, Y.. (2006) Numerical simulation studies of the different vegetation patterns' effects on outdoor pedestrian thermal comfort. The Forth International Symposium on Computational Wind Engineering, Yokohama, Japan

[12]. Teller, J.; Azar, S.(2001) TOWNSCOPE II - A computer system to support solar access decisionmaking. International Journal of Solar Energy, 70(3): pp187-200

[13]. ASHRAE (2009) ASHRAE Handbook - Fundamentals (SI Edition), American Society of Heating, Refrigerating, and Air-Conditioning Engineers, Inc.2009

[14]. Mardaljevic, J. (1995) Validation of Lighting Simulation Program under Real Sky conditions. Lighting Research \& Technology 27(4): pp181-188

[15]. Reinhart C. Walkenhorst, O. (2001) Validation of dynamic RADIANCE-based daylight simulations for a test office with external blinds. Energy and Buildings 33, pp683-697

[16]. Ward, G.; Shakespeare, R.(1998) Rendering with RADIANCE: The Arts and Science of Lighting Visualization. Morgan Kaufmann Publishers

[17]. Jakubiec, J.; Reinhart, C. (2011) DIVA-FOR-RHINO 2.0: Environmental parametric modeling in Rhinoceros/Grasshopper using RADIANCE, Daysim and EnergyPlus. Conference Proceedings of Building Simulation 2011, Sydney, Australia

[18]. McNeel, R. (2010) Rhinoceros - NURBS Modeling for Windows (version 4.0), McNeel North America, Seattle, WA, USA Available at www.rhino3d.com Retrieved May 2012

[19]. Reindl, D.; Beckman, W.; Duffie, J.(1990) Diffuse Fraction Correlations, Solar Energy 45:pp1-7

[20]. Angstrom, A. (1918) A study of the radiation of the atmosphere. Smithsonian Miscellaneous Collection, 65 
[21]. Flerchinger, G.; Xiao, W.; Marks, D.; Sauer, T.; Yu, Q.(2009) Comparison of algorithms for incoming atmospheric long-wave radiation. Water Resources Research, Vol. 45

[22]. Buck, A.(1981) New equations for computing vapor pressure and enhancement factor. Journal of Applied Meteorology. 20: pp1527-1532

[23]. Underwood C.; Ward E.(1966) The solar radiation area of man. Ergonomics 9: pp155-168

[24]. Kuehn, L.; Stubbs, R..;Weaver, R.(1970) Theory of the globe thermometer. Journal of Applied Physiology 29

[25]. Boston Redevelopment Authority (BRA) (2012) Research and Maps, available at http://www.bostonredevelopmentauthority.org/research-maps. Retrived Dec. 2011

[26]. Perez, R.; Stewart, R.; Seals, R.; Guertin, T. (1988) The Development and Verification of the Perez Diffuse Radiation Model, Sandia National Laboratory Contractor Report SAND88-7030 